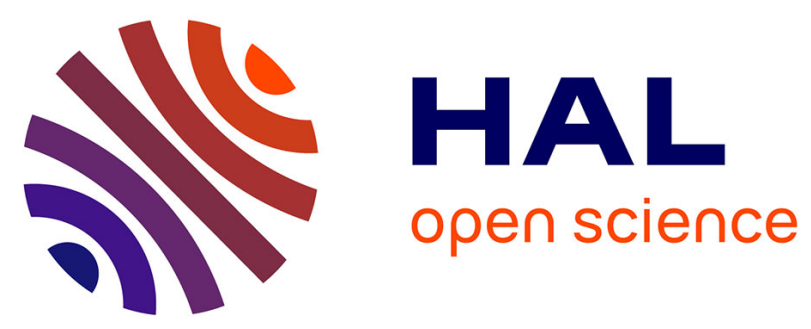

\title{
Remobilization of polycyclic aromatic hydrocarbons and organic matter in seawater during sediment resuspension experiments from a polluted coastal environment: Insights from Toulon Bay (France)
}

Catherine Guigue, Marc Tedetti, Duc Huy Dang, Jean-Ulrich Mullot, Cédric Garnier, M. Goutx

\section{To cite this version:}

Catherine Guigue, Marc Tedetti, Duc Huy Dang, Jean-Ulrich Mullot, Cédric Garnier, et al.. Remobilization of polycyclic aromatic hydrocarbons and organic matter in seawater during sediment resuspension experiments from a polluted coastal environment: Insights from Toulon Bay (France). Environmental Pollution, 2017, 229, pp.627-638. 10.1016/j.envpol.2017.06.090 . hal-01635969

\section{HAL Id: hal-01635969 https://hal.science/hal-01635969}

Submitted on 20 Apr 2018

HAL is a multi-disciplinary open access archive for the deposit and dissemination of scientific research documents, whether they are published or not. The documents may come from teaching and research institutions in France or abroad, or from public or private research centers.
L'archive ouverte pluridisciplinaire HAL, est destinée au dépôt et à la diffusion de documents scientifiques de niveau recherche, publiés ou non, émanant des établissements d'enseignement et de recherche français ou étrangers, des laboratoires publics ou privés. 
Remobilization of polycyclic aromatic hydrocarbons and organic matter in seawater during sediment resuspension experiments from a polluted coastal environment: insights from Toulon Bay (France)

Catherine Guigue $^{\mathrm{a},{ }^{*}}$, Marc Tedetti ${ }^{\mathrm{a}}$, Duc Huy Dang ${ }^{\mathrm{b} 1}$, Jean-Ulrich Mullot ${ }^{\mathrm{c}}$, Cédric Garnier ${ }^{\mathrm{b}}$, Madeleine Goutx ${ }^{\mathrm{a}}$

${ }^{a}$ Aix Marseille Université, CNRS/INSU, Université de Toulon, IRD, Mediterranean Institute of Oceanography (MIO) UM 110, 13288, Marseille, France

baboratoire PROTEE, EA 3819, Université de Toulon, BP 20132, 83957 La Garde, France

${ }^{\mathrm{c}}$ LASEM-Toulon, Base Navale de Toulon, BP 61, 83800 Toulon, France

* Corresponding author: catherine.guigue@ mio.osupytheas.fr; Phone: +33(0)4 860905 25; Fax: $+33(0) 491829641$

Final version for Environmental Pollution as full research article

11 June 2017

\footnotetext{
${ }^{1}$ Present address: School of the Environment, Trent University, 1600 West Bank Drive, Peterborough, ON, K9L 0G2, Canada
} 


\begin{abstract}
Polycyclic aromatic hydrocarbons (PAHs) and organic matter contents were measured in seawater during resuspension experiments using sediments collected from Toulon Bay (Northwestern Mediterranean Sea, France). The studied sediments were very highly contaminated in PAHs, especially in 4-ring compounds emitted from combustion processes. The sediments used for resuspension experiments were collected at 0-2 cm (diagenetically new organic matter, $\mathrm{OM}$ ) and 30-32 cm depths (diagenetically transformed $\mathrm{OM}$ ). They were both mostly composed of fine particles $(<63 \mu \mathrm{m})$, enriched in organic carbon $(8.2$ and $6.3 \%$, respectively) and in PAHs (concentration of $\Sigma 34$ PAHs: 38.2 and $35.2 \times 10^{3} \mathrm{ng} \mathrm{g}^{-1}$, respectively). The resuspension of these sediments led to an increase in concentrations of dissolved 234 PAHs, dissolved organic carbon (DOC) and dissolved humic- and tryptophan-like fluorophores in seawater up to 10-, 1.3-, 4.4- and 5.7-fold, respectively. The remobilization in seawater was higher for 4-6 ring PAHs, especially benzo(g,h,i) perylene, whose concentration exceeded the threshold values of the European Water Framework Directive. This noted the potential harmful effects of sediment resuspension on marine biota. From these sediment resuspension experiments, we determined OC-normalized partition coefficients of PAHs between sediment and water $\left(\mathrm{K}_{\mathrm{oc}}\right)$ and found that during such events, the transfer of PAHs from sediment particles to seawater was lower than that predicted from octanol-water partition coefficients $\left(\mathrm{K}_{\mathrm{ow}}\right)$ (i.e., measured $\mathrm{K}_{\mathrm{oc}}>\mathrm{K}_{\mathrm{oc}}$ predicted from $\mathrm{K}_{\mathrm{ow}}$ ). The results confirmed the sequestration role of sedimentary OC quality and grain size on PAHs; the OM diagenetic state seemed to impact the partition process but in a relatively minor way. Furthermore, differences were observed between 2-4 ring and 5-6 ring PAHs, with the latter displaying a relatively higher mobility towards seawater. These differences may be explained by the distribution of these two PAH pools within different OM moieties, such as humic substances and black carbon.
\end{abstract}


Keywords: Sediment resuspension, remobilization, polycyclic aromatic hydrocarbons, fluorescent dissolved organic matter, sediment-water partition.

\section{Introduction}

Polycyclic aromatic hydrocarbons (PAHs) are among the most widespread organic pollutants in marine environments. Due to their hydrophobicity and low water solubility, PAHs entering marine waters tend to sorb onto particulate organic matter (OM) (Gustafsson et al., 2001; Kennish, 1992; May, 1978) that is then deposited to the sediments via vertical sinking. This mechanism is recognized as a major pathway for the removal and global cycling of hydrocarbons in the ocean (Adhikari et al., 2015; Berrojalbiz et al., 2011; Gustafsson et al., 1997). However, due to natural (waves, currents, storms) and anthropogenic (dredging, trawling, ship traffic) forcing, coastal sediments are frequently resuspended, refocused and transported along the continental shelf (Durrieu de Madron et al., 2008; Schoellhamer, 1996) and thus may turn into a potential source of organic pollutants, including PAHs, for the water column (Dong et al., 2015; Eggleton and Thomas, 2004). While natural forcing generally induces the resuspension of surface sediments (the first centimeters), human activities, particularly dredging or harbor improvements, may lead to the resuspension over sediment depths of several dozens of centimeters. Dissolved PAHs originating from sediment resuspension may then have harmful effects for organisms living in the water column (Gewurtz et al., 2007; Varanasi et al., 1985; Woodhead et al., 1999).

The partitioning of PAHs between water and sediment evaluated through the determination of the sediment-water or sediment OM-water partition coefficients $\left(\mathrm{K}_{\mathrm{d}}\right.$ or $\mathrm{K}_{\mathrm{oc}}$, respectively) is largely driven by grain size and OM content of sediments and may vary during resuspension 
events (Cornelissen et al., 2006; Karickhoff et al., 1979; Rockne et al., 2002; Tremblay et al., 2005). However, little is known about the association between PAHs and sedimentary OM subjected to transformations during burial and diagenesis (Berner, 1980; Henrichs, 1993); that is, the change in $\mathrm{K}_{\mathrm{d}}$ and $\mathrm{K}_{\mathrm{oc}}$ values with sediment depth or OM aging. Further, studies dealing with PAH partitioning between water and sediment should better consider the interactions between dissolved PAHs and dissolved OM (DOM) (Akkanen et al., 2005; McCarthy and Jimenez, 1985; Yang et al., 2016). Over the last decade, the dynamics of DOM in coastal waters has been evaluated through the study of its fluorescent fraction (FDOM). Recently, FDOM associated with marine or river sediments has been characterized, i.e., the FDOM from sediment pore waters (Burdige et al., 2004; Dang et al., 2014; Sierra et al., 2001) and from sediment particles (Brym et al., 2014; Dang et al., 2014; He et al., 2016), as well as FDOM released by coastal sediment resuspension (Komada et al., 2002). Hence, due to the influence of OM in PAH partitioning processes, it is generally observed that theoretical $\mathrm{K}_{\mathrm{oc}}$, i.e., $\mathrm{K}_{\mathrm{oc}}$ predicted from their octanol-water partition coefficients $\left(\mathrm{K}_{\mathrm{ow}}\right)$, are lower than measured $\mathrm{K}_{\mathrm{oc}}$ (Accardi-Dey and Gschwend, 2002; Feng et al., 2007; Fernandes et al., 1997). As a corollary, concentrations in water that are determined from sediment concentrations and theoretical $\mathrm{K}_{\mathrm{oc}}$ are frequently overestimated. This also leads to an over-estimation of uptake processes and/or effects of those chemicals on exposed organisms (Arp et al., 2009; Hawthorne et al., 2007). Measuring $\mathrm{K}_{\mathrm{oc}}$ is thus essential for more accurate predictions of PAH toxicity in the water column.

In the Mediterranean Sea, Toulon harbor (Southern France, Northwestern Mediterranean Sea) hosts the main French Navy structure. It is located deep inside Toulon Bay and enclosed by a sea wall. Because of this separation, and also the irregular freshwater inputs and the low tide, water circulation in this part of the Bay is limited, leading to low water regeneration and potentially strong accumulation of chemical contaminants such as PAHs in the sediments 
(Benlahcen et al., 1997; Misson et al., 2016; Wafo et al., 2016). To maintain a navigable water depth, harbor dredging is regularly required in accordance with the current legislation. Such dredging may induce a sediment resuspension over $100 \mathrm{~cm}$ sedimentary depths, thus allowing surface and deep sediments to be resuspended. Since surface and deep sediments have different OM contents (from potentially different origins along with diagenetic transformations with time/depth), their resuspension could generate various remobilization kinetics of pollutants in seawater. Several studies have reported high concentrations of trace metals, metalloids and organometallics during Toulon Bay seabed disturbances (Cossa et al., 2014; Dang et al., 2015a, Pougnet et al.,2014; Tessier et al.,2011). In addition, Dang et al. (2015b) demonstrated that Pb was significantly released in seawater and further transferred to organisms such as mussels during resuspension experiments on surface and deep sediments from Toulon Bay. Nevertheless, to our knowledge, no data are available describing PAH remobilization during sediment resuspension events in such a strongly dredged and multi-contaminated area.

Therefore, in the present study, we carried out supplementary experiments simulating the resuspension of surface and deep sediments in Toulon Bay, as proposed by Dang et al. (2015b). Our objectives were (i) to assess the contamination level and origin of PAHs in a sediment core from Toulon Bay, (ii) to evaluate the effect of surface and deep sediment resuspension on the remobilization of $\mathrm{PAH}$ and $\mathrm{OM}$, as well as on the water quality, and (iii) to compare theoretical and measured $\mathrm{K}_{\mathrm{oc}}$ to better understand the factors controlling PAH remobilization during sediment resuspension experiments (SRE). To our knowledge, this study represents the first assessment of remobilization kinetics of both dissolved PAHs and DOM during SRE involving surface and deep sediments.

\section{Materials and Methods}




\subsection{Study area}

Located on the French Northwestern Mediterranean coast, Toulon city is a part of a large urban area of approximately $500 \times 10^{3}$ inhabitants. Toulon Bay is divided into two unequal basins, a small basin $\left(9.8 \mathrm{~km}^{2}\right.$, semi-enclosed) submitted to various anthropogenic inputs (the French Navy, commercial traffic, raw sewage from the urban area, industries) and a large basin $\left(42.2 \mathrm{~km}^{2}\right)$ that is less impacted and open to the sea (Fig. 1). Toulon harbor is situated in the small bay, which is the discharge area for the watershed. Low tides in the Mediterranean Sea associated with weak currents in this area of Toulon Bay have significant implications for the accumulation of contaminants in sediments (Dufresne et al., 2014; Tessier et al., 2011).

\subsection{Sampling and sample treatment}

Sediments and seawater were collected at the Missiessy (MIS) site within the nuclear submarine harbor of the French Navy, on May $5^{\text {th }} 2014$, with the support of the French Navy (ship, material, divers) (Fig. 1).

\subsubsection{Sediment core}

A sediment core of ca. $50 \mathrm{~cm}$ was collected through the use of an interface corer (Plexiglas tube, $10 \mathrm{~cm}$ diameter and $1 \mathrm{~m}$ long), by Navy divers keeping undisturbed the bottom water column and the upper sediment column, and so preserving the water-sediment interface as described in Dang et al. (2014, 2015a), Tessier et al. (2011). The collected sediment core was maintained vertically and was carefully transferred (by boat and then van) to the laboratory before being installed on a home-made slicing table under glove box. The core was sliced with a 2-cm resolution under inert atmosphere $\left(\mathrm{N}_{2}\right)$ to preserve oxidation-reduction (redox) conditions. 
Each slice was then homogenized in a $150 \mathrm{~mL}$ high-density-polyethylene bottle and split into $3 \times$ $50 \mathrm{~mL}$ polypropylene centrifuge tubes under $\mathrm{N}_{2}$ atmosphere. Then, porewater was extracted by centrifugation ( $15 \mathrm{~min}, 20^{\circ} \mathrm{C}, 400 \mathrm{rpm}$, Sigma 3-18 K), recovered under $\mathrm{N}_{2}$ atmosphere by filtration $(0.2-\mu \mathrm{m}$ on-line syringe filters, cellulose nitrate, Sartorius) and stored in required vessels depending on further chemical analyses. Such methodology was successfully applied to study depth profile variation of main diagenesis tracers and OM characteristics (Chen and Hur, 2015). In accordance with previous studies on trace element sedimentary dynamics in the same area (Dang et al., 2015b), two slice samples were selected from this sediment core to perform SRE: the 0-2 cm sediment layer (denoted hereafter "0-2 cm sediment") and the $30-32 \mathrm{~cm}$ sediment layer (denoted hereafter “30-32 cm sediment”) (see $§ 2.3$ ). The PAH concentrations were determined in each layer of the core (freeze-drying and $2 \mathrm{~mm}$ sieving) to assess the contamination level and potential toxicity of PAHs at this specific site. In addition to PAHs, particle grain size, organic carbon and nitrogen (OC and $\mathrm{ON})$ contents, and aliphatic hydrocarbons (AHs) were determined in the 0-2 and 30-32 cm sediment layers dedicated to SRE. Additionally, porewater measurements of $\mathrm{pH}$, redox potential (Eh), dissolved organic carbon (DOC), dissolved inorganic carbon (DIC), total nitrogen $\left(\mathrm{N}_{\mathrm{T}}\right)$, ammonium $\left(\mathrm{NH}_{4}{ }^{+}\right)$, soluble reactive phosphorus $(\mathrm{SRP})$, silicate $\left(\mathrm{Si}(\mathrm{OH})_{4}\right)$, manganese $\left(\mathrm{Mn}_{\mathrm{T}}\right)$, iron $\left(\mathrm{Fe}_{\mathrm{T}}\right)$, sulfate $\left(\mathrm{SO}_{4}{ }^{2-}\right)$ and total sulfide $\left(\Sigma \mathrm{HS}^{-}\right)$were taken to verify the redox status of these two sediments according to previously described procedures (Dang et al., 2014, 2015a, 2015b).

\subsubsection{Seawater}

Seawater was collected to characterize the water column in the small basin of the bay in terms of PAH and DOM concentrations and to conduct SRE. Samples were taken in duplicates at $0.5,2.5,5$ and $13 \mathrm{~m}$ (overlying water $\sim 1 \mathrm{~m}$ above the sediments) depths using a 2.2-L Wildco 
Van-Dorn horizontal water sampler. Before use, the latter was rinsed with $3 \times 1 \mathrm{~L}$ of ultrapure (Milli-Q) water acidified to $0.2 \% \mathrm{HCl}$ (TraceSelect, Fluka) and then several times with sampling water. The water samples were poured into polycarbonate bottles (Nalgene). Before use, the bottles were washed with $1 \mathrm{M} \mathrm{HCl}$ followed by a wash with ultrapure water and three washes with the respective sample.

At the laboratory, the water samples were immediately filtered under a low vacuum $(<50$ $\mathrm{mm} \mathrm{Hg}$ ) through precombusted $\left(450{ }^{\circ} \mathrm{C}, 6 \mathrm{~h}\right)$ glass fiber filters $(\mathrm{GF} / \mathrm{F}, \sim 0.7 \mu \mathrm{m}, 47 \mathrm{~mm}$ diameter, Whatman) using all-glassware systems for dissolved PAHs, DOC and FDOM. The filtered samples for dissolved PAH analyses were stored in 2-L SCHOTT glass bottles with $50 \mathrm{~mL}$ dichloromethane $\left(\mathrm{CH}_{2} \mathrm{Cl}_{2}\right)$ at $4{ }^{\circ} \mathrm{C}$ in the dark before solvent extraction (within $24 \mathrm{~h}$ ) while the samples for DOC and FDOM were stored frozen until analysis.

\subsection{Sediment resuspension experiments}

The solid/liquid (S/L) ratio was set at $\sim 1 \mathrm{~g} \mathrm{~L}^{-1}$ (expressed in dry weight), a value close to in situ levels of suspended particulate matter measured during surface sediment reworking as previously published (Dang et al., 2015b). To apply this ratio for each experiment, $\sim 11 \mathrm{~g}$ of wet sediment from the $0-2 \mathrm{~cm}$ slice (62\% moisture) and $\sim 8 \mathrm{~g}$ of wet sediment from the $30-32 \mathrm{~cm}$ slice (52\% moisture) were introduced into $4 \mathrm{~L}$ Nalgene bottles filled with $0.7-\mu \mathrm{m}$ filtered surface seawater (collected at $0.5 \mathrm{~m}$ depth). The bottles were then placed on roller agitation devices (Wheaton, $8 \mathrm{rpm})$ at room temperature $\left(21-23^{\circ} \mathrm{C}\right)$. Experiments lasted 14 days and were run in duplicate (i.e., four $4 \mathrm{~L}$ bottles in total). The water subsamples were collected at 1, 3, $7 \mathrm{~h}$ and 1, 3, 7, 10, 14 days and were analyzed for dissolved PAHs, DOC and FDOM. For each subsample, agitation was stopped for approx. 30 min allowing most of the sediment particles to settle. Then, $400 \mathrm{~mL}$ of water was collected from the top of the bottle and immediately filtered for analysis. 
To minimize S/L ratio variation, the same volume $(400 \mathrm{~mL})$ of filtered initial seawater was added to the bottle after each subsampling. Because subsamples were taken several minutes after stopping agitation, the loss of sediment particles from this successive subsampling was estimated to be negligible over the course of the SRE (Dang et al., 2015b). Also, according to Dong et al. (2016), such short stops cannot be considered as successive sediment resuspension-deposition events. It should be noted that the biological activity was not stopped in these experiments since (i) any added poison could have affected OM measurements and (ii) our aim was to mimic the $\mathrm{PAH}$ and $\mathrm{OM}$ sorption/desorption as close as possible to the natural conditions.

\subsection{Hydrocarbon analysis}

\subsubsection{Hydrocarbon extraction and purification}

PAHs were measured in each layer of the whole sediment core and in seawater samples (water column profile and SRE), while AHs were measured only in the 0-2 and 30-32 cm sediments used for SRE. Hydrocarbons (PAHs and AHs) were extracted from sediment samples in $5 \mathrm{~mL}$ cells with $\mathrm{CH}_{2} \mathrm{Cl}_{2}$ and copper powder to remove elemental sulfur, using pressurized liquid extraction (trade name ASE for accelerated solvent extraction) with a Dionex ASE 350 system $\left(150{ }^{\circ} \mathrm{C}, 110\right.$ bars, 3 cycles of $10 \mathrm{~min}, 100 \%$ of rinsing, purging for $60 \mathrm{~s}$; ThermoElectron). Dissolved PAHs present in the fraction $<0.7 \mu \mathrm{m}$ (water column profile and SRE) were extracted from water by liquid-liquid extraction with $\mathrm{CH}_{2} \mathrm{Cl}_{2}(2 \times 80 \mathrm{~mL}$ per liter). The protocol was then the same for sediment and water extracts. The solvent volume was reduced by rotary evaporation and the solvent was changed to $n$-hexane prior to purification. The hexanesolubilized extracts were purified to separate hydrocarbons from more polar compounds. These extracts were fractionated on a 500-mg silica column. Silica gel (extra pure, Merck) was 
activated at $450{ }^{\circ} \mathrm{C}$ for $6 \mathrm{~h}$ followed by partial deactivation with $4 \%$ water by weight. The extracts were deposited using 2-mL $n$-hexane and hydrocarbons were eluted with $3-\mathrm{mL} n$ hexane $/ \mathrm{CH}_{2} \mathrm{Cl}_{2}(3: 1 \mathrm{v} / \mathrm{v})$ (Guigue et al., 2011, 2014, 2015). All solvents were of organic traceanalysis quality (Rathburn Chemicals Ltd.).

\subsubsection{Analysis of hydrocarbons}

The purified extracts were analyzed by gas chromatography-mass spectrometry (GC-MS) (TraceISQ, ThermoElectron) operating at an ionization energy of $70 \mathrm{eV}$ for a $\mathrm{m} / \mathrm{z}$ range of 50400 (full scan and selected ion monitoring (SIM) modes processed simultaneously), using helium as carrier gas at a flow rate of $1.2 \mathrm{~mL} \mathrm{~min}^{-1}$. The GC-MS was equipped with a HP-5 MS ultrainert column $(30 \mathrm{~m} \times 0.25 \mathrm{~mm} \times 0.25 \mu \mathrm{m}, \mathrm{J} \& \mathrm{~W}$ Scientific, Agilent Technologies $)$. The injector (used in splitless mode) and detector temperatures were 270 and $320{ }^{\circ} \mathrm{C}$, respectively. The initial column temperature was held for $3 \mathrm{~min}$ at $70{ }^{\circ} \mathrm{C}$, then ramped at $15{ }^{\circ} \mathrm{C} \mathrm{min}-1$ (ramp 1) to $150{ }^{\circ} \mathrm{C}$ and then at $7{ }^{\circ} \mathrm{C} \min ^{-1}$ (ramp 2) to a final temperature of $320{ }^{\circ} \mathrm{C}$, which was held for $60 \mathrm{~min}$. AHs and PAHs were identified and quantified in scan and SIM modes simultaneously using two distinct methods (Guigue et al., 2011, 2014).

\subsubsection{Quality assurance and quality control}

All glassware was washed with $1 \mathrm{M} \mathrm{HCl}$ and ultrapure water and combusted at $450{ }^{\circ} \mathrm{C}$ for 6 h. All the materials that could not be baked were washed with $1 \mathrm{M} \mathrm{HCl}$ and ultrapure water and dried at room temperature.

Standard mixtures (04071, Fluka and 47543-U, Supelco among others) and natural samples (for alkylated homologue PAHs) were used to validate the identification methods. Further, deuterated standard mixtures $\left(\mathrm{C}_{16}-d_{34}\right.$ and Naph- $d_{8}$ for lower MW compounds, i.e., $<n-\mathrm{C}_{20}$ alkanes 
and 2-ring PAHs, $\mathrm{C}_{24}-d_{50}$ and Phe- $d_{10}$ for medium MW compounds, i.e., $n-\mathrm{C}_{20}-n-\mathrm{C}_{29}$ alkanes and 3-4 ring PAHs, $\mathrm{C}_{36}-d_{74}$ and Per- $d_{12}$ for higher MW compounds, i.e., $>n-\mathrm{C}_{30}$ alkanes and 5-6 ring PAHs) were introduced as surrogates before extraction, as well as a supplementary deuterated standard ( $\left.\mathrm{Chr}-d_{12}\right)$ before injection, to assess the procedural recoveries and to refine the quantification of hydrocarbons in the samples. The recoveries of Naph- $d_{8}$, Phe- $d_{10}$ and Per- $d_{12}$ were on average 44, 61 and $81 \%$ in water and 54, 73 and $93 \%$ in sediment samples, respectively. Caution was taken during the evaporation because dryness could lead to the complete loss of the more volatile compounds. In addition, blanks were run for the whole procedure including the use of the Nalgene polycarbonate bottles, extraction, solvent concentration and purification. All concentration values were blank- and recovery-corrected (procedure fully described in Guigue et al., 2015). Instrumental detection limits for individual compounds varied from 1 to $30 \mathrm{pg}$ of injected chemical. No certified reference standard is currently available for PAHs in water but the protocol for sediment was validated based on the agreement of individual compound quantification compared to NIST, 1941b (organics in sediment) (agreement of $97 \pm 10 \%$ ).

\subsubsection{Determination of individual hydrocarbons}

For PAHs, we determined the concentrations of 19 parent PAHs and alkylated homologues of the target compounds Naph, Flu, Phe/Ant, Flt/Pyr and Chr, leading to a total of 34 PAHs (see full names of PAHs in Text S1). Naph and its alkylated homologues are 2-ring compounds. Acy, Ace, Flu, DBT, Phe, Ant and alkylated homologues of Flu, Phe and Ant are 3-ring compounds. Flt, Pyr, BaA, Chr and alkylated homologues of Flt, Pyr and Chr are 4-ring compounds. BbF, $\mathrm{BkF}, \mathrm{BaP}$, Per and DBA are 5-ring, while BP and IndP are 6-ring, compounds. Concerning AHs, we determined the concentrations of the resolved $n$-alkane series $(R)$ from $n$ - $\mathrm{C}_{15}$ to $n$ - $\mathrm{C}_{36}$ with two isoprenoids, pristane (Pr) and phytane (Phy), as well as the unresolved complex mixture 
(UCM) concentrations. All ratios and indices used to determine $\mathrm{PAH}$ and $\mathrm{AH}$ potential origins are given in the supplementary material (see Text S1).

\subsection{Sediment grain size and contents in total organic carbon and nitrogen}

Grain size and total OC and ON contents were determined for the $0-2$ and $30-32 \mathrm{~cm}$ sediment layers. Grain size was determined with a Beckman Coulter LS 13320 laser granulometer after OM removal (Ghilardi et al., 2012). The relative abundance of sand (2000 to $63 \mu \mathrm{m})$, silt (63 to $2 \mu \mathrm{m})$ and clay $(<2 \mu \mathrm{m})$ was then measured. Contents in OC and ON were determined simultaneously, after acidification, with an AutoAnalyser II Technicon using the wet oxidation procedure (Raimbault et al., 1999). The contents are expressed as a percentage (\%) of sed. dw.

\subsection{Dissolved organic matter measurements}

DOC was determined by high-temperature catalytic oxidation using a Shimadzu TOC 5000 Total Carbon Analyzer (Kyoto, Japan) according to Sohrin and Sempéré (2005). Two replicates were analyzed for each sample. The concentrations are the mean of the two replicates with a coefficient of variance $(\mathrm{CV})<2 \%$.

FDOM analyses were performed with a Hitachi F-7000 spectrofluorometer (Tokyo, Japan). The method is fully described in Tedetti et al. $(2012,2016)$ and Ferretto et al. (2014). Briefly, excitation-emission matrices (EEMs) were generated for excitation wavelengths $\left(\lambda_{\mathrm{Ex}}\right)$ between 230 and $500 \mathrm{~nm}$ and for emission wavelengths $\left(\lambda_{\mathrm{Em}}\right)$ between 280 and $550 \mathrm{~nm}$. Two replicates were run for each sample. To correct EEMs for potential inner filtering effects, dilution method was used. Fluorescence intensities were blank-corrected and converted to quinine sulfate units (QSU), where 1 QSU corresponds to the fluorescence of $1 \mu \mathrm{g} \mathrm{L}^{-1}$ quinine sulfate in $0.05 \mathrm{M}$ 
sulfuric acid at $\lambda_{\mathrm{Ex}} / \lambda_{\mathrm{Em}}$ of $350 / 450 \mathrm{~nm}$ (5nm slit widths). The fluorescence intensities in QSU provided for each sample are the mean of the two replicates with a $\mathrm{CV}<8 \%$. The data were processed using parallel factor analysis (PARAFAC) operated using the DOMFluor toolbox v1.6. running under MATLAB 7.10.0 (R2010a). The PARAFAC model was created and validated for 81 samples according to the method of Stedmon and Bro (2008).

\subsection{Determination of sediment-water partition coefficients of PAHs}

The partition coefficients of PAHs between sediment and water $\left(\mathrm{K}_{\mathrm{d}}\right)$ were determined using the following equation:

$$
\mathrm{K}_{\mathrm{d}}=\mathrm{C}_{\mathrm{p}} / \mathrm{C}_{\mathrm{d}}
$$

where $C_{p}$ is the concentration of individual PAHs in sediment $\left(n g \mathrm{~kg}^{-1}\right)$ and $\mathrm{C}_{\mathrm{d}}$ is the concentration in the water-dissolved phase $\left(\mathrm{ng} \mathrm{L}^{-1}\right)$. The OC-normalized partition coefficients of PAHs between sediment and water $\left(\mathrm{K}_{\mathrm{oc}}\right)$ were then calculated using the following equation:

$$
\mathrm{K}_{\mathrm{oc}}=\mathrm{K}_{\mathrm{d}} / \mathrm{f}_{\mathrm{oc}}
$$

where $\mathrm{f}_{\mathrm{oc}}$ is the fraction of organic carbon in resuspended sediment particles (\% OC in Table 2$)$. The values for $\log \mathrm{K}_{\mathrm{d}}$ and $\log \mathrm{K}_{\mathrm{oc}}$ were computed for the 16 priority PAHs.

\subsection{Statistics}

Student's $t$-test, used to compare the mean of two independent data groups, and Pearson's linear correlation matrices, as well as non-linear regression analyses were carried out using XLSTAT 2013.5.01 (Microsoft Excel add-in program). For the different analyses and tests, the significance threshold was set at $\mathrm{p}<0.05$. 


\section{Results and discussion}

\subsection{Characterization of sediment and water from the MIS site}

\subsubsection{Contamination levels and origin of PAHs in the sediment core}

In the first $40 \mathrm{~cm}$ of the sediment core, $\Sigma 34 \mathrm{PAH}$ concentrations varied between $30.7 \times 10^{3}$ at the $10-12 \mathrm{~cm}$ depth and $123 \times 10^{3} \mathrm{ng} \mathrm{g}^{-1}$ sed. $\mathrm{dw}$ at the $36-38 \mathrm{~cm}$ depth, with a high value of 231 $\times 10^{3} \mathrm{ng} \mathrm{g}^{-1}$ sed. $\mathrm{dw}$ recorded at the $24-26 \mathrm{~cm}$ depth (Fig. S1). The PAH concentrations in the surface layer of the MIS sediment core were in agreement with previous recordings from the MIS site $\left(34.0 \times 10^{3} \mathrm{ng} \mathrm{g}^{-1}\right.$; Misson et al., 2016) and in the Toulon coastal area $\left(48.1 \times 10^{3} \mathrm{ng} \mathrm{g}^{-1}\right.$; Benlahcen et al., 1997). The PAH concentrations we recorded in the whole core were in the upper-range of values reported for sediments from other regions of the Mediterranean Sea (see Table 6 in Zaghden et al., 2017). For instance, they were close to the highest values measured in the surface sediments from the Taranto Gulf, Italy $\left(28.9-262 \times 10^{3} \mathrm{ng} \mathrm{g}^{-1}\right.$ sed. $\mathrm{dw}$; Annicchiarico et al., 2011). The environmental quality guidelines are detailed in the supplementary material (Text S2). The 16 priority PAHs displayed concentrations above L1 and ERL levels at almost all sediment depths and above L2 and ERM levels at many depths (Table 1), which mirrors high to extreme pollution levels according to both JORF and SQG, in agreement with previous results for trace elements from the small basin of Toulon Bay (Tessier et al., 2011).

The profile shape of $\Sigma 34$ PAH concentrations with depth at MIS was in good agreement with previous studies showing disturbed sedimentation during the past (raising of a scuttled warship) and the present (harbor extension) activities (Fig. S1; Dang et al., 2015b; Misson et al., 2016). Despite episodic events disturbing sedimentation, the surface layers are considered to be more recent than deeper ones (Dang et al., 2015b; Tessier et al., 2011). The surprising value of $231 \times$ 
$10^{3} \mathrm{ng} \mathrm{g}^{-1}$ recorded at $24-26 \mathrm{~cm}$, which had a similar molecular distribution to the other layers (data not shown), might not be attributed to a special historic period/contamination but more probably to the heterogeneity in the vertical distribution of sediment particles or to the presence of a tiny piece of coal block.

The PAH molecular distribution in the sediment core barely varied with depth and was dominated by 4-ring compounds, as shown for the 0-2 and 30-32 cm sediments in Fig. 2. This distribution reflected the dominance of Flt and Pyr, which has been observed in other coastal areas of the Mediterranean Sea (Ben Othman et al., 2017; Pérez-Fernández et al., 2015). The isomeric ratios were quite close from one depth to another, and showed that PAHs in the MIS sediment more probably originated from combustion processes, especially of grass/wood/coal, rather than from burned/unburned petroleum residues (Fig. S2). The dominance of pyrogenic PAHs in this sediment is in agreement with our knowledge of current and past activities at Toulon harbor (loading dock for coal and coal-fired Navy vessels) and also reflects a highly anthropized coastal environment subjected to important watershed and atmospheric particulate inputs (Fig. S2; Vane et al., 2014; Yunker et al., 2002). Nevertheless, it is worth recalling that isomeric ratios have to be used with caution for the determination of PAH origin because they may evolve with time or with the distance from emission sources (Katsoyiannis and Breivik, 2014).

\subsubsection{Comparison of the 0-2 and 30-32 cm sediments}

The 0-2 and 30-32 cm sediments used for SRE were exclusively composed of fine particles < $63 \mu \mathrm{m}$ : 69 and $82 \%$ of silt, 31 and $18 \%$ of clay, respectively. Their OC content was 8.2 and $6.3 \%$, respectively (Table 2). The predominance of silts, which promote the accumulation of contaminants, and the OC content in these sediments are in good agreement with previous studies 
from Toulon Bay (Dang et al., 2014; Tessier et al., 2011). Additionally, the OC content was in the upper range of that reported for surface sediments of the Northern Mediterranean Sea (from 0.38 to $6.2 \%$ ) (Benlahcen et al., 1997; Lipiatou and Saliot, 1991).

The $\mathrm{C} / \mathrm{N}$ ratios in the $0-2$ and $30-32 \mathrm{~cm}$ sediments (13.5 and 22, respectively) (Table 2) were higher than typical values reported for most coastal sediments $(\mathrm{C} / \mathrm{N}=6-10$; Wang et al., 2001) but lower than that of the alkaline-extracted OM previously recorded in this area $(\mathrm{C} / \mathrm{N}=36 \pm 9$; Dang et al., 2014). The $\mathrm{C} / \mathrm{N}$ ratio may provide information about the OM origin, as well as the diagenetic degradation state. A high $\mathrm{C} / \mathrm{N}$ ratio (> 20) reveals a terrestrial origin of $\mathrm{OM}$ due to the low N percentage in the higher vegetation (Emerson and Hedges, 1988; Muller, 1977). On the other hand, a low C/N ratio (5-7) implies a marine origin (plankton or seaweeds) (Meyers, 1994). In addition, it has previously been demonstrated that the buried particulate OM in Toulon Bay (at another location than MIS) is N-, P- and Si-depleted, due to the sedimentary OM mineralization and transformation processes (Dang et al., 2014). This depletion could result in increases in the $\mathrm{C} / \mathrm{N}$ ratio. In the present case, the $\mathrm{C} / \mathrm{N}$ ratios suggest a mixed origin, with both terrestrial and autochthonous marine sources at both depths along with higher diagenetic processes at the 30-32 cm depth (N-depletion; Table 2) according to Dang et al. (2014).

The porewaters of the two studied sediment layers were slightly acidic and enriched in DOC, DIC, $\mathrm{NH}_{4}{ }^{+}, \mathrm{SRP}, \mathrm{Si}(\mathrm{OH})_{4}$ and $\mathrm{Fe}_{\mathrm{T}}$ compared to seawater, showing important diagenesis processes (Table $\mathrm{S} 1$ ), and differed in their redox status. The $0-2 \mathrm{~cm}$ sediment porewaters had positive Eh $(109 \mathrm{mV} / \mathrm{ENH})$ and high $\mathrm{Fe}_{\mathrm{T}}$ concentrations $(70.2 \mu \mathrm{M})$ typical of oxidizing conditions, while the $30-32 \mathrm{~cm}$ sediment porewaters displayed negative Eh (-145 $\mathrm{mV} / \mathrm{ENH})$ and much lower $\mathrm{Fe}_{\mathrm{T}}$ concentrations $(7.7 \mu \mathrm{M})$, reflecting reducing conditions. Additionally, they had differences in DOC (367 and $717 \mu \mathrm{M}$, respectively), $\mathrm{N}_{\mathrm{T}}(104$ and $173 \mu \mathrm{M}), \mathrm{NH}_{4}{ }^{+}(72.6$ and 54.8 $\mu \mathrm{M}$, respectively) and $\mathrm{Mn}_{\mathrm{T}}$ (2.3 and $0.7 \mathrm{nM}$, respectively) concentrations (Table $\mathrm{S} 1$ ). 
The $\Sigma 34$ PAH concentrations in these samples were 38.2 and $35.7 \times 10^{3} \mathrm{ng} \mathrm{g}^{-1}$ sed. dw, respectively (Fig. S1; Table 2) and all 16 priority compounds showed concentrations above L1 and ERL levels. Additionally, Ace and BaA in the 0-2 cm sediment and Phe, Pyr, BaP and DBA in the 0-2 and 30-32 cm sediments had concentrations above the L2 and ERM levels (Table 1). For both the sediment layers, as in the whole core, 2-ring compounds accounted on average for $8 \%$ of total PAHs, 3-rings for 17\%, 4-rings for $41 \%$ (with a high contribution of Flt and Pyr), 5rings for $22 \%$ and 6-rings for $11 \%$ (Fig. 2).

The $R$ concentrations ( $n$ - $\mathrm{C}_{15}$ to $n$ - $\mathrm{C}_{36}$ with $\mathrm{Pr}$ and Phy) were 2.4 and $10.0 \times 10^{3} \mathrm{ng} \mathrm{g}^{-1}$ sed. $\mathrm{dw}$ with $\mathrm{UCM} / R$ values of 30 and 118 , respectively (Table 2). The $R$ values were relatively low compared to the PAH content of these sediments and were situated in the middle-lower range of $n$-alkane concentrations reported from other Mediterranean environments (see Table 4 in Zaghden et al., 2017). For example, they were of the same order of magnitude as those determined in the Gulf of Tunis (1.8 and $10.0 \times 10^{3} \mathrm{ng} \mathrm{g}^{-1}$ sed. dw; Mzoughi and Chouba, 2011). The $R$ and $\mathrm{UCM} / R$ values were four times higher at the $30-32 \mathrm{~cm}$ than at the $0-2 \mathrm{~cm}$ depth. The $R$ molecular profiles were characterized by bi-modal distributions. Odd-carbon numbered dominated the $n$-alkane patterns: $n-\mathrm{C}_{17}$ for the LMW compound profiles $\left(\leq n-\mathrm{C}_{24}\right)$ and $n-\mathrm{C}_{29}, n$ $\mathrm{C}_{31}$ and $n-\mathrm{C}_{33}$ for the HMW compound profiles $\left(>n-\mathrm{C}_{24}\right)$ (Fig. S3). This led to CPI values slightly above $1 . \mathrm{CPI}_{15-24}$ was 1.3 in both sediments, showing that autochthonous algal material and anthropogenic $n$-alkanes accounted for 13 and $87 \%$ of total $n$-alkanes, respectively. $\mathrm{CPI}_{25-36}$ was 2.9 and 2.2 in the $0-2$ and 30-32 cm sediments, respectively. This underscores that continental higher plant debris $n$-alkanes accounted for 49 and 37\%, and anthropogenic $n$-alkanes for 51 and $63 \%$ of total $n$-alkanes, respectively (Table 2$)$. In both sediments, these results $(R, \mathrm{UCM} / R, \mathrm{CPI}$ values) reflected the superposition of compounds originating from biogenic and anthropogenic inputs, as well as their incomplete degradation (Blumer et al., 1971; Bouloubassi and Saliot, 
1993; Douglas and Eglinton, 1966). However, compared to the 0-2 cm sediment, the $30-32 \mathrm{~cm}$ sediment presented a higher anthropogenic fingerprint along with a higher diagenetic state. This greater anthropization level was very likely due to the Second World War and activities during and after this period (Tessier et al., 2011). The higher contribution of Phy at this depth might also be attributed to the diagenetic state of sediments, even though diagnostics using isoprenoid compounds must be taken with caution (Grossi et al., 1998; Rontani and Bonin, 2011).

In conclusion, $\mathrm{C} / \mathrm{N}$ ratios, diagenetic tracers in porewaters and $\mathrm{AHs}$ showed that the $0-2 \mathrm{~cm}$ sediment was globally less contaminated, presenting more biogenic inputs, especially terrigenous, and was more recent/less degraded or diagenetic transformed than the $30-32 \mathrm{~cm}$ sediment. This finding confirmed the differences already reported in previous studies combining redox potential and particulate OM aging (Dang et al., 2014, 2015b). The OM aging of sediment particles might play a role in PAH-OM interactions and therefore on the PAH mobility during seabed disturbances, as suspected for other organic contaminants (Calvo et al., 1991). In contrast, PAH distribution did not make it possible to highlight such differences between the two sediments.

\subsubsection{Characterization of the water column}

The concentrations of dissolved $\Sigma 34$ PAHs in the water column were $2.8 \pm 0.7,2.1 \pm 0.5,3.8$ \pm 1.5 and $4.6 \pm 0.9 \mathrm{ng} \mathrm{L}^{-1}$ at $0.5,2.5,5$ and $13 \mathrm{~m}$ depths, respectively (Fig. S4a). Dissolved PAHs were dominated by 2 - and 3-ring compounds (38 \pm 9 and $49 \pm 10 \%$, respectively), whereas 4 - and 5-rings represented only $10 \pm 2$ and $3 \pm 7 \%$, respectively, with 6-ring compounds being under the detection limits (Fig. 2). These concentrations are in the lower range of those previously observed in some Northwestern Mediterranean coastal areas, whereas the molecular distribution (dominance of 2-3 ring compounds) was in agreement with these studies (Guigue et al., 2011, 2014; Guitart et al., 2004). 
DOC concentrations were $79.4 \pm 1.3,75.6 \pm 1.0,74.8 \pm 1.0$ and $76.0 \pm 0.2 \mu \mathrm{M}$ at $0.5,2.5,5$ and 13 m depths, respectively (Fig. S4b). These concentrations were in the same range as those previously measured in this area (Dang et al., 2014). PARAFAC applied to EEMs revealed the presence of two main FDOM fluorophores in seawater (for both depth profiles and SRE). One fluorophore displayed two fluorescence maxima at $\lambda_{\mathrm{Ex} 1}, \lambda_{\mathrm{Ex} 2} / \lambda_{\mathrm{Em}}$ of $230,340 / 452 \mathrm{~nm}$. This humic-like fluorophore corresponds to peaks A + C in Coble's (1996) classification and to component 2 in Ishii and Boyer's (2012) classification. The other, with two fluorescence maxima located at $\lambda_{\mathrm{Ex} 1}, \lambda_{\mathrm{Ex} 2} / \lambda_{\mathrm{Em}}$ of $230,280 / 348 \mathrm{~nm}$, corresponds to a tryptophan-like fluorophore, i.e., peaks T1 + T2 according to Coble (1996) and Hudson et al. (2007) (contour plots of PARAFAC components not shown). It should be noticed that this fluorophore could also indicate the presence of PAHs and specifically naphthalene, whose fluorescence spectral domain is superimposed on that of tryptophan (Tedetti et al., 2010; Ferretto et al., 2014). However, the sum of Naph and alkylated Naph homologue concentrations measured here $\left(<5 \mathrm{ng} \mathrm{L}^{-1}\right)$ in water were not high enough to generate such fluorescence signatures (detection limit of Naph by EEM method; $1 \mu \mathrm{g} \mathrm{L}^{-1}$; Ferretto et al., 2014). The fluorescence intensities of humic- and tryptophanlike fluorophores at $0.5,2.5,5$ and $13 \mathrm{~m}$ depths were $2.7 \pm 1.2,3.5 \pm 0.9,2.9 \pm 0.3$ and $4.0 \pm 0.3$ QSU (Fig. S4c) and 4.8 $\pm 2.4,6.2 \pm 1.4,7.4 \pm 0.7$ and 8.4 \pm 1.6 QSU, respectively (Fig. S4d).

These two fluorophores have been reported in several coastal environments, including the Northwestern Mediterranean Sea (Ferretto et al., 2017; Para et al., 2010; Tedetti et al., 2012). The tryptophan-like fluorophore represents free amino acids or amino acids bound as peptides or proteins. It is known to serve as a fresh and labile bioavailable product for heterotrophic bacteria (Romera-Castillo et al., 2010; Yamashita and Tanoue, 2004). The humic-like fluorophore has maximal absorption in the UVC and UVA wavelengths. It is more hydrophobic, more condensed and more photodegradable compared to the tryptophan material, as indicated by its higher $\lambda_{\mathrm{Ex}}$ and 
$\lambda_{\mathrm{Em}}$. Dang et al. (2014) and Hur et al. (2014) detected these two fluorophores (humic and tryptophan) in sediment particles after an alkaline extraction, showing that they could also originate from sediment, in addition to the water column. According to Dang et al. (2014), the tryptophan-like fluorophore would be derived from fresh POC in surface sediments, while humiclike fluorophore would be either produced by the hydrolysis of the buried HMW-POM or by the geo-polymerization of LMW-DOM. Overall, these data show that water from $0.5 \mathrm{~m}$ depth was not subjected to an important recent remobilization and was well adapted to forthcoming experiments.

\subsection{Remobilization of PAHs and OM during sediment resuspension experiments (SRE)}

\subsubsection{Dissolved phase enrichment}

Concentrations of dissolved $\Sigma 34$ PAHs, DOC and FDOM fluorophores in water over the course of the 0-2 and 30-32 cm SRE are presented in Fig. 3. The standard deviation (to estimate the variance) is given for the two-bottle replicates $(n=2)$. For the four parameters, both SRE led first to an immediate (within one hour after the sediment addition) release in water. This fast PAH release in the dissolved phase (within the first hour) was also observed by Yang et al. (2008). Then, from the first hour to the end (14 days) of the SRE, concentrations in water tended to increase: from $8.6 \pm 1.6$ to $24 \pm 9.9 \mathrm{ng} \mathrm{L}^{-1}$ (Fig. 3a) and from $9.5 \pm 3.9$ to $12 \pm 5.4 \mathrm{ng} \mathrm{L}^{-1}$ (Fig. 3b) for dissolved $\Sigma 34$ PAHs, from $87 \pm 0.2$ to $91 \pm 0.3 \mu \mathrm{M}$ (Fig. 3c) and from $89 \pm 1.4$ to $98 \pm$ $2.9 \mu \mathrm{M}$ (Fig. 3d) for DOC, from $5.4 \pm 0.1$ to $11 \pm 1.8$ QSU (Fig. 3e) and from $4.8 \pm 0.9$ to $11 \pm$ 0.2 QSU (Fig. 3f) for the humic-like fluorophore, and from $9.1 \pm 0.3$ to $28 \pm 3.2$ QSU (Fig. 3g) and from $8.0 \pm 1.4$ to $15 \pm 0.9$ QSU (Fig. 3h) for the tryptophan-like fluorophore. These results seem to be in agreement with desorption biphasic models of organic compounds from 
soils/sediments, i.e., a rapid desorption phase of PAHs adsorbed onto particles followed by a more slowly desorbing phase of PAHs strongly bound into particles (Karickhoff and Morris, 1985; Mitra and Dickhut, 1999; Van Noort, et al., 2003).

Enrichment factors (EFs, computed as the ratios of the concentration in water at time t over that at the initial time; that is, just before sediment addition) for dissolved PAHs, DOC and the humic-like fluorophore were quite similar between the 0-2 and 30-32 cm SRE, ranging from 2.68.5 and 2.5-10 (PAHs), 1.1-1.2 and 1.1-1.3 (DOC), and 2.0-4.2 and 1.8-4.4 (humic), respectively (Fig. 3a-f). For the tryptophan-like fluorophore, they were clearly higher in the 0-2 cm SRE (1.75.7) than in the 30-32 cm SRE (1.7-3.2) (Fig. 3g,h). EFs recorded here for PAHs were of the same order of magnitude as those reported in previous studies under natural conditions (Dong et al., 2015).

\subsubsection{Change in dissolved PAH distribution profile}

During SRE, all the individual PAHs investigated were, to some extent, released into the dissolved phase. For both SRE, dissolved PAH distribution profiles were dominated by 3-ring compounds (33 \pm 8 and $38 \pm 8 \%$ of total PAHs) (Fig. 2). Moreover, in the range of 2-4-ring compounds, SRE PAH profiles were clearly intermediate between (and significantly different from) that of the water column (0.5-13 m depths; dominated by 3-ring compounds, accounting for $49 \pm 10 \%$ of total PAHs) and those of sediments (dominated by 4-ring compounds, accounting for 39 and $43 \%$ of total PAHs) (Fig. 2). However, for 5- and 6-ring compounds, the relative abundances were much closer between SRE (16-19 and 6-7\%, respectively) and sediments (21-24 and 11-12\%, respectively). Hence, compared to the water column, the remobilization of PAHs led to a shift in the molecular structure profiles towards HMW compounds, with a decrease in the relative abundances of 2- and 3-ring compounds (by 49 and 
$29 \%$ on average, respectively), an increase in the relative abundances of 4- and 5-ring compounds (by 115 and $414 \%$ on average, respectively) and the appearance of 6-ring compounds (Fig. 2).

\subsubsection{Comparison of the remobilization kinetics between surface and deep sediments}

Remobilization kinetics were studied by following dissolved PAH and DOM concentration evolution, as well as correlations between these parameters within each SRE. First, to help in comparing the behavior of parameters between each other and between the two experiments, we sought to model the kinetic patterns. Several models obtained by least square fits were tested (linear, exponential, power, logarithmic, polynomial of degrees 2-3). The polynomial function of degree 3 (cubic functions) best fitted our data. All these cubic relationships were significant $(\mathrm{r}=$ $0.78-1.00, \mathrm{p} \leq 0.0001-0.02, \mathrm{n}=8)$, except for DOC in the 30-32 $\mathrm{cm} \mathrm{SRE}(\mathrm{r}=0.72, \mathrm{p}=0.06, \mathrm{n}=$ 7; Fig. 3d). Nevertheless, we observed some differences in the shape of these cubic functions between the $0-2 \mathrm{~cm}$ and the $30-32 \mathrm{~cm}$ SRE.

In the 0-2 cm SRE, DOC and the tryptophan-like fluorophore presented a cubic curve with a negative leading coefficient (-0.045 and -0.005 , respectively; Fig. 3c,g). Dissolved PAHs and humic-like fluorophores presented a different pattern due to the positive leading coefficient of their equation (0.031 and 0.002, respectively; Fig. 3a,e). In addition, maximal values for PAHs and the humic- and tryptophan-like fluorophores were recorded at the end of the experiment $(\mathrm{t}=$ 14 days) of $24 \pm 9.9 \mathrm{ng} \mathrm{L}^{-1}, 11 \pm 1.8$ and $28 \pm 3.2$ QSU, respectively (Fig. 3a,e,g), whereas that of DOC was found at $\mathrm{t}=10$ days $(99 \pm 2.9 \mu \mathrm{M})$ (Fig. 3c). Only humic- and tryptophan-like fluorophore intensities were significantly linearly correlated for the $0-2 \mathrm{~cm} \mathrm{SRE}(\mathrm{r}=0.98, \mathrm{p}=$ 0.0003, $\mathrm{n}=8$ ) (Table 3).

In contrast, for the 30-32 cm SRE, leading coefficients were all positive (Fig. 3b,f,h). For dissolved PAHs and the humic-like fluorophore, maximal values $\left(29 \pm 20 \mathrm{ng} \mathrm{L}^{-1}\right.$ and $12 \pm 1.5$ 
QSU, respectively) were found at $t=7$ days (Fig. 3b,f). Those for DOC concentration $(100 \pm 8.5$ $\mu \mathrm{M})$ and the tryptophan-like fluorophore $(15 \pm 0.9$ QSU) were observed at $\mathrm{t}=3$ days (Fig. $3 \mathrm{~d}$ ) and $t=14$ days (Fig. 3h), respectively. For the 30-32 cm SRE, the correlation between humicand tryptophan-like fluorophores was still observed $(\mathrm{r}=0.92, \mathrm{p}=0.001, \mathrm{n}=8)$, but in addition, significant linear correlations were found between dissolved PAHs and the humic-like fluorophore $(\mathrm{r}=0.75, \mathrm{p}=0.025, \mathrm{n}=8)$ and between DOC and the tryptophan-like fluorophore $(\mathrm{r}$ $=0.78, \mathrm{p}=0.04, \mathrm{n}=7$ ) (Table 3). These correlations are further investigated in $\S 3.3 .3$.

In the present study, the adjustment of dissolved concentrations to functions of degree 3 is in agreement with Delle Site (2001) and Karickhoff et al. (1979), who presented the sorption processes of a chemical from one phase to another as the result of a reversible reaction (sorptiondesorption) reaching a final equilibrium condition between the concentrations of the chemical in the two phases. One can even suspect redistribution of the chemical between and within phases. Furthermore, the significant leading coefficient being mainly positive suggested that the dissolved $\Sigma 34$ PAH and DOM patterns for the two SRE may evidence such successive processes: first, desorption from particles related to dissolution or colloid formation from particle collisions that can be followed by some sorption onto/into particles or new aggregations (because of change in polarity or oxygenation conditions for example, especially for the $30-32 \mathrm{~cm}$ sediment) and, possibly, some bacterial degradation and volatilization occurring at different time scales between parameters and the two sediments. Even though sorption cubic models globally fit for the two SRE, the remobilization patterns of dissolved PAHs and DOM during SRE appeared to be sediment-dependent. Accordingly, Dang et al. (2015b) also observed different remobilization patterns for $\mathrm{Pb}$ between the $0-2 \mathrm{~cm}$ and $30-32 \mathrm{~cm}$ sediment that were attributed to differences in the oxidation degree, which is further linked to differences in the OM diagenetic state (see $\S$ 3.1.2.) of these two sediments. 


\subsection{Factors influencing the PAH sediment-water partitioning}

Partition coefficients $\left(\mathrm{K}_{\mathrm{d}}\right.$ and $\mathrm{K}_{\mathrm{oc}}$ ) are key parameters to understand and describe the distribution of PAHs between sediment and water. The $\log \mathrm{K}_{\mathrm{d}}$ and $\log \mathrm{K}_{\mathrm{oc}}$ values for PAHs found in the literature display great variability. Even though it is clear that $\mathrm{K}_{\mathrm{d}}$ and $\mathrm{K}_{\mathrm{oc}}$ are related to physico-chemical characteristics of the compounds, the variability between studies would come from the strong heterogeneity in the nature/composition of sedimentary particles and OM, which influence the whole sediment sorption capacity.

\subsubsection{Hydrophobicity of PAHs}

The values for $\log \mathrm{K}_{\mathrm{oc}}$ we determined here were plotted versus the corresponding $\log \mathrm{K}_{\mathrm{ow}}$ in Fig. 4. A strong positive significant correlation was observed between $\log \mathrm{K}_{\mathrm{ow}}$ and the measured $\log \mathrm{K}_{\mathrm{oc}}$ for the 2-4 ring PAHs for both SRE:

For 0-2 cm SRE: $\log \mathrm{K}_{\mathrm{oc}}=0.59 \times \log \mathrm{K}_{\mathrm{ow}}+4.9(\mathrm{r}=0.89, \mathrm{p}=0.001, \mathrm{n}=10)$

For 30-32 cm SRE: $\log \mathrm{K}_{\mathrm{oc}}=0.64 \times \log \mathrm{K}_{\mathrm{ow}}+4.7(\mathrm{r}=0.91, \mathrm{p}<0.0001, \mathrm{n}=10)$

The equations ( $a$ and $b, r=0.89-0.91$ ) revealed that the linear free energy relationship was applicable for 2-4 ring PAHs. The $\log \mathrm{K}_{\mathrm{oc}}$ values for the 5-6 ring compounds diverged from the 2-4 ring compound linearity area (Fig. 4). They were lower than expected from equation (a) or (b), and very close to each other, depicting a plateau. They were also closer to $\log \mathrm{K}_{\mathrm{ow}}$ values and to $\log K_{\mathrm{oc}}$ predicted from Bouloubassi and Saliot (1992) and Means et al. (1980). These results confirmed that the hydrophobicity of the concerned PAHs remains an essential factor for their partitioning between water and suspended particles. This is in agreement with most of the previous studies (Accardi-Dey and Gschwend, 2003; Bouloubassi and Saliot, 1992; Dong et al., 
2015). However, it is not the only factor, because (i) the $\log \mathrm{K}_{\mathrm{oc}}$ measured here were generally above $\log \mathrm{K}_{\mathrm{ow}}$ (Fig. 4), as observed in several studies (Bouloubassi and Saliot, 1992; Feng et al., 2007; Rockne et al., 2002), and above $\log \mathrm{K}_{\mathrm{oc}}$ measured in previous studies dealing with the resuspension of sediment or porewater contents (Table S2), (ii) the slopes of the linear regressions for the 2-4 ring PAH were $<1$ ( 0.59 and 0.64$)$, which is in accordance with numerous studies, showing that sediment retention capacity was higher for lower MW than for higher MW PAHs (2->3->4-rings) (Bouloubassi and Saliot, 1992; Cao et al., 2015; Fernandes et al., 1997), (iii) the mobility of 5-6 ring PAH diverged from that of 2-4 rings, suggesting that the transport processes differed between these two groups (Feng et al., 2007), and (iv) the remobilization kinetics for the surface and deep sediment were shown to be sediment-dependent. For all of these reasons, other factors, such as sedimentary grain size and OM quality, were suspected to play an important role in PAH partitioning.

\subsubsection{Sedimentary grain size and $O M$ quality}

In this work, sediments were characterized by fine-grained particles that promote the accumulation of hydrophobic compounds such as PAHs (Yang et al., 2008). Concerning OM sorption capacities, Cornelissen and Gustafsson (2004 and references therein) support the dualmode sorption concept. The latter suggests that sedimentary OM retention is due to absorption into amorphous OM, including biopolymers and humic substances (HS), and adsorption onto carbonaceous geosorbents, including unburned coal, kerogen and black carbon (BC). HS and BC are as two major effective sorbents for PAHs in sediment particles (Delle Site, 2001; Khan and Shnitzer, 1972; Cornelissen and Gustafsson., 2004). Cornelissen et al. (2005) supported that important content in carbonaceous geosorbents might explain 1-2 order of magnitude higher $\mathrm{K}_{\mathrm{oc}}$ values. HS and BC were not measured in the sediment in the present work. Nonetheless, humic- 
like material was evidenced in these Toulon sediments by Dang et al. (2014) and we can reasonably make the assumption of a high presence of sedimentary soot BC because of PAHs originating mainly from combustion-residue-sources (Fig. S2, Readman et al., 1987; Zhou et al., 1999) that can be both released in seawater during our SRE (Dong et al., 2016; Kaal et al., 2016). Therefore, the 2-4 ring and 5-6 ring PAHs could have been partitioned differently between HS and BC, which both present peculiar binding capacities.

The decoupling between 2-4 and 5-6 ring compounds could also be linked to the association of these two groups of PAHs with different sedimentary particle sizes. Indeed, Karickhoff et al. (1979) and Latimer et al. (1999) showed that HMW PAHs are preferentially associated with larger size particles and will therefore have different transport characteristics and fate. In the present case, coarse silts would display lower active surface area, leading to lower retention capacities than the finer ones. This may also explain the relatively higher mobility of 5-6 ring PAHs towards the dissolved phase compared to LMW PAHs.

\subsubsection{DOM}

Due to the complexity of interactions driving the PAH partitioning between water and sediment, it is very likely that such contaminants were distributed into three phases: the first phase (solid phase, sediment), the second phase (solution phase, water) and the third phase (colloidal or DOM-associated phase) (Delle Site, 2001). Within the third phase, the formation of PAH-DOM complexes may increase the transfer of PAHs towards the dissolved phase (Dong et al., 2016). The effect of the third phase is known to be more pronounced for compounds exhibiting higher hydrophobicity ( $\log \mathrm{K}_{\mathrm{ow}}>5$ ) (Delle Site, 2001; Dong et al., 2016).

The remobilization of dissolved PAHs, especially during the 30-32 cm SRE, seemed to be associated with the release of dissolved/colloidal diagenetic HS (correlation between PAHs and 
humic-like fluorophore; Table 3, Dang et al., 2015b). This is consistent with the fact that this humic-like fluorophore in the Toulon sediment would arise from the OM diagenetic transformation (Dang et al., 2014). We may assume that these dissolved PAHs released from sediment concomitantly to humic-like material were present in water both as free compounds and as complexes with DOM, which in turn might substantially modify their fate in the water column (Hur et al., 2014; Kim and Kwon, 2010; Sabbah et al., 2004). The coupling between PAHs and HS could be favored by the anoxic/diagenetic state of this deep sediment, since previous studies have shown that the binding capacity between PAHs and HS was negatively related to the oxidation degree and positively related to the OM humification degree (Chen et al. 2010; He and Wang, 2011; Perminova et al., 1999).

Consequently, the relative higher mobility of 5-6 ring compounds towards the dissolved phase we observed here, already highlighted by Mitra et al. (1999), could be explained by their interactions with HS (third phase effect), which would be in accordance with observations from Delle Site (2001). However, a detailed correlation analysis revealed that only 2-4 ring compounds displayed a significant correlation with HS at the 30-32 $\mathrm{cm}$ depth $(\mathrm{r}=0.81, \mathrm{p}=0.013, \mathrm{n}=8)$, while 5-6 rings did not correlate $(\mathrm{r}=0.51, \mathrm{p}=0.21, \mathrm{n}=8)$ (not shown in Table 3 ). This does not necessarily exclude the hypothesis of the third phase distribution for 5-6 ring PAHs, but rather suggests that the latter would occur from their interaction with other OM moieties. Since PAHs in sediment most likely originated from combustion processes, the mobility of 5-6 ring PAHs could be related preferentially to the release of dissolved black carbon (Kaal et al., 2016).

\subsubsection{Equilibration time}

In parallel to previous conclusions, the present high $\log \mathrm{K}_{\mathrm{oc}}$ values may be explained by the non-equilibrium partition status. Many authors indicated that partition coefficients measured in 
non-equilibrium situations can lead to errors in $\log \mathrm{K}_{\mathrm{oc}}$ (Delle Site, 2001). Moreover, if the suspected bi-phase desorption model is effective in the present case, the fast release might have taken a short time $(1 \mathrm{~h})$ but the total equilibrium may need months to years to be achieved (Delle Site, 2001 and references therein). Thus, considering the remobilization kinetics, it is very likely that the equilibrium between phases has not been reached and concentrations in the dissolved phase were expected to continue to increase. In spite of this, we aimed to focus on real conditions of few-to-many-day dredging resuspension sediments, and we thought this work might provide useful insight into processes that control PAH fate and transport.

\subsection{Impact of the MIS sediment resuspension on water quality}

Although the sediment from the MIS site was very highly contaminated and in spite of the PAH dissolved enrichment during the presented experiments, the concentrations of individual PAHs in water during both SRE remained far below the EU WFD MAC-EQS, except for one compound, BP, which exceeded by 3.8 (0-2 cm SRE)- to 5.1 (30-32 cm SRE)-fold the threshold value of $0.82 \mathrm{ng} \mathrm{L}^{-1}$ (Table 4). These BP concentrations showed that sediment resuspension in Toulon Bay may lead to potential harmful effects on the biota (Feng et al., 2007). However, BP (6-ring compound) may be most likely associated with colloids or DOM, which might in turn reduce its bioavailability and toxicity.

\section{Conclusion}

Sediment at the MIS site (Toulon Bay) appears to be one of the most contaminated sediments of the Mediterranean coasts in terms of PAHs and trace elements. Sediment resuspension is a 
geochemically significant process for PAHs and OM in coastal environments. The two simulated SRE showed 2- to 6-ring PAH remobilization from the sediment to the dissolved phase, increasing seawater concentrations, up to 10 -fold. These concentrations remained, however, below the toxicity thresholds, limiting potential adverse effects, except for BP. The PAH transfer from the Toulon sediment to water was lower than predicted from $\log \mathrm{K}_{\mathrm{ow}}$, confirming the sequestration role of such a fine-grained and OC-enriched sediment for hydrophobic contaminants. The remobilization patterns of dissolved PAHs and DOM were different for the two sediments very likely due to their respective diagenetic state and redox status. Additionally, the difference in the relationships between $\log \mathrm{K}_{\mathrm{ow}}$ and $\log \mathrm{K}_{\mathrm{oc}}$ for 2-4 ring PAHs and 5-6 ring PAHs may be explained by their partition between different OM moieties, i.e., HS and BC, respectively, but also different particle grain sizes, i.e., finer and larger, respectively. Additional experiments would be necessary to discriminate the roles of the particle size and associated OM, as well as weathering processes (degradation, volatilization), particularly for LMW PAHs, on the sediment-water PAH partitioning at this site. The combination of sedimentary OM and insufficient equilibration time may easily explain 2-3 order of magnitude higher $\mathrm{K}_{\mathrm{oc}}$ values compared to other studies. Resuspension of sediments remains a complex issue to interlink particle concentrations with the degradation of water quality and the living organism exposure. These results should be considered for the future management operations and environmental policy in polluted coastal areas such as Toulon harbor.

Acknowledgements. This study was funded and performed in the framework of CNRS MISTRALS MERMEX-WP3-C3A research program. We are grateful to the French Navy for logistical support and sampling assistance. We thank the Service d'Observation of the Mediterranean Institute of Oceanography and the core parameter platform, both managed by P. 
Raimbault. We acknowledge the granulometry platform of the CEREGE, managed by D. Delanghe, for OC, ON and particle grain size analyses, as well as G. Wassouf for FDOM analyses. Three anonymous reviewers are acknowledged for their relevant comments. 


\section{References}

Accardi-Dey, A., Gschwend, P.M., 2002. Assessing the Combined Roles of Natural Organic Matter and Black Carbon as Sorbents in Sediments. Environmental Science and Technology $36,21-29$.

Accardi-Dey, A., Gschwend, P.M., 2003. Reinterpreting Literature Sorption Data Considering both Absorption into Organic Carbon and Adsorption onto Black Carbon. Environmental Science and Technology 37, 99-106.

Adhikari, P.L., Maiti, K., Overton, E., 2015.Vertical fluxes of polycyclic aromatic hydrocarbons in the northern Gulf of Mexico. Marine Chemistry, 168, 60-68.

Annicchiarico, C., Buonocore, M., Cardellicchio, N., Di Leo, A., Giandomenico, S., Spada, L., 2011. PCBs, PAHs and metal contamination and quality index in marine sediments of the Taranto Gulf. Chemistry in Ecology 27, 21-32.

Akkanen, J., Tuikka, A., Kukkonen, J.V.K., 2005. Comparative Sorption and Desorption of Benzo[a]pyrene and 3,4,3',4'-Tetrachlorobiphenyl in Natural Lake Water Containing Dissolved Organic Matter. Environmental Science and Technology 39, 7529-7534. Arp, H.P.H., Breedveld, G., Cornelissen, G., 2009. Estimating the in situ Sediment-Porewater Distribtuion of PAHs and Chlorinated Aromatic Hydrocarbons in Anthropogenic Impacted Sediments. Environmental Science and Technology 43, 5576-5585.

Benlahcen, K.T., Chaoui, A., Budzinski, Bellocq, J., Garrigues, P., 1997. Distribution and Sources of Polycyclic Aromatic Hydrocarbons in some Mediterranean Coastal Sediments. Marine Pollution Bulletin 34, 298-305.

Ben Othman, H., Pringault, O., Louati, H., Sakka Hlaili A., Leboulanger, C., 2017. Impact of contaminated sediment elutriate on coastal phytoplankton community (Thau lagoon, 
Mediterranean Sea, France). Journal of Experimental Marine Biology and Ecology 486, 112.

Berner, R.A., 1980. Early Diagenesis: A Theoretical Approach ( $1^{\text {st }}$ edn). Princeton University Press, Princeton, 241 pp.

Berrojalbiz, N., Dachs, J., Ojeda, M.J., Valle, M.C., Castro-Jiménez, J., Wollgast, J., Ghiani, M., Hanke, G., Zaldivar, J.M., 2011. Biogeochemical and physical controls on concentrations of polycyclic aromatic hydrocarbons in water and plankton of the Mediterranean and Black Seas. Global Biogeochemical Cycles 25, 1-14, doi:10.1029/2010GB003775.

Blumer, M., Guillard, R.R.L., Chase, T., 1971. Hydrocarbons of marine phytoplankton. Marine Biology 8, 183-189.

Bouloubassi, I., Saliot, A., 1992. Rôle des fleuves dans les apports de contaminants organiques aux zones côtières: cas des hydrocabures aromatiques polycycliques (HAP) dans le delta du Rhône (Mediterranée Nord-Occidentale). Océanis (Paris), 549-562.

Bouloubassi, I., Saliot, A., 1993. Investigation of anthropogenic and natural organic inputs in estuarine sediments using hydrocarbon markers (NAH, LAB, PAH). Oceanologica Acta 16, $145-161$.

Brym, A., Paerl, H.W., Montgomery, M.T., Handsel, L.T., Ziervogel, K., Osburn, C.L., 2014. Optical and chemical characterization of base-extracted particulate organic matter in coastal marine environments. Marine Chemistry 162, 96-113.

Burdige, D.J., Kline, S.W., Chen, W., 2004. Fluorescent dissolved organic matter in marine sediment pore waters. Marine Chemistry 89, 289-311.

Calvo, C., Grasso, M., Gardenghi, G., 1991. Organic Carbon and Nitrogen in Sediments and in Resuspended Sediments of Venice Lagoon : Relationships with PCB Contamination. Marine Pollution Bulletin 22, 543-547. 
Cao, Q.M., Wang, H., Qin, J.Q., Chen, G.Z., Zhang, Y.B., 2015. Partitioning of PAHs in pore water from mangrove wetlands in Shantou, China. Ecotoxicology and Environmental Safety $111,42-47$.

Chen, M., Hur, J., 2015. Pre-treatments, characteristics, and biogeochemical dynamics of dissolved organic matter in sediments: A review. Water Research 79, 10-25.

Chen, S., Xu, Y., Wang, Z., 2010. Assessing desorption resistance of PAHs in dissolved humic substances by membrane-based passive samplers. Journal of Colloid and Interface Science, $350,348-354$.

Coble, P.G., 1996. Characterization of marine and terrestrial DOM in seawater using excitation emission matrix spectroscopy. Marine Chemistry 51, 325-346.

Cornelissen, G., Breedveld, G.D., Kalaitzidis, S., Christanis, K., Kibsgaard, A., Oen, A.M.P., 2006. Strong Sorption of Native PAHs to Pyrogenic and Unburned Carbonaceous Geosorbents in Sediments. Environmental Science and Technology 40, 1197-1203.

Cornelissen, G., Guftafsson, O., 2004. Sorption of Phenanthrene to Environmental Black Carbon in Sediment with and without Organic Matter and Native Sorbates. Environmental Science and Technology 38, 148-155.

Cornelissen, G., Gustafsson, O., Bucheli, T.D., Jonker, M.T.O., Koelmans, A.A., Van Noort, P.C.M., 2005. Extensive Sorption of Organic Compounds to Black Carbon, Coal, Kerogen in Sediments and Soils: Mechanisms and Consequences for Distribution, Bioaccumulation, and Biodegradation. Environmental Science and Technology 39, 6881-6895.

Cossa, D., Garnier, C., Buscail, R., Elbaz-Poulichet, F., Mikac, N., Patel-Sorrentino, N., Tessier, E., Rigaud, S., Lenoble, V., Gobeil, C., 2014. A Michaelis-Menten type equation for 
describing methylmercury dependence on inorganic mercury in aquatic sediments. Biogeochemistry 119, 35-43.

Dang, D.H., Lenoble, V., Durrieu, G., Mullot, J.-U., Mounier, S., Garnier, C., 2014. Sedimentary dynamics of coastal organic matter: An assessment of the porewater size/reactivity model by spectroscopic techniques. Estuarine, Coastal and Shelf Science, 151, 100-111.

Dang, D.H., Lenoble, V., Durrieu, G., Omanović, D., Mullot, J.-U., Mounier, S., Garnier, C., 2015a. Seasonal variations of coastal sedimentary trace metals cycling: Insight on the effect of manganese and iron (oxy)hydroxides, sulphide and organic matter. Marine Pollution Bulletin 92, 113-124.

Dang, D.H., Schäfer, J., Brach-Papa, C., Lenoble, V., Durrieu, G., Dutruch, L., Chiffoleau, J.-F., Gonzalez, J.-L., Blanc, G., Mullot, J.-U., Mounier, S., Garnier, C., 2015b. Evidencing the impact of coastal contaminated sediments on mussels through $\mathrm{Pb}$ stable isotopes composition. Environmental Science and Technology 49, 11438-11448.

Delle Site, 2001. Factors affecting Sorption of Organic Compounds in Natural Sorbent/Water Systems and Sorption Coefficients for Selected Pollutants. A Review. Journal of Physical and Chemical Reference Data 30, 187-430.

Dong, J., Xia, X., Wang, M., Lai, Y., Zhao, P., Dong, H., Zhao, Y., Wen, J., 2015. Effect of water-sediment regulation of the Xiaolangdi Reservoir on the concentrations, bioavailability, and fluxes of PAHs in the middle and lower reaches of Yellow River. Journal of Hydrology $527,101-112$.

Dong, J., Xia, X., Wang, M., Xie, H., Wen, J., Bao, Y., 2016. Effects of recurrent sediment reuspension-deposition events on bioavailability of polycyclic aromatic hydrocarbons in aquatic environments. Journal of Hydrology 540, 934-946. 
Douglas, A.G., Eglinton, G., 1966. Distribution of alkanes. In: Swam, T. (eds.). Comparative Phytochemistry. Academic Press, London, New York, pp. 57-77.

Dufresne, C., Duffa, C., Rey, V., 2014. Wind-forced circulation model and water exchanges through the channel in the Bay of Toulon. Ocean Dynamics 64, 209-224.

Durrieu de Madron, X., Wiberg, P., Puig, P., 2008. Sediment dynamics in the Gulf of Lions: The impact of extreme events. Continental Shelf Research 28, 1867-1876.

Eggleton, J., Thomas, K.V., 2004. A review of factors affecting the release and bioavailability of contaminants during sediment disturbance events. Environment International 30, 973-980.

Emerson, S., Hedges, J.I., 1988. Processes controlling the organic carbon content of open ocean sediments. Paleoceanography 3, 621-634.

Feng, J., Yang, Z., Niu, J., Shen, Z., 2007. Remobilization of polycyclic aromatic hydrocarbons during the resuspension of Yangtze River sediments using a particle entrainment simulator. Environmental Pollution 149, 193-200.

Fernandes, M.B., Sicre, M-A., Boireau, A., Tronczynski, J., 1997. Polyaromatic Hydrocarbon (PAH) Distribution in the Seine River and its Estuary. Marine Pollution Bulletin 34, 857-867. Ferretto, N., Tedetti, M., Guigue, C., Mounier, S., Redon, R., Goutx, M., 2014. Identification and quantification of known polycyclic aromatic hydrocarbons and pesticides in complex mixtures using fluorescence excitation-emission matrices and parallel factor analysis. Chemosphere 107, 344-353.

Ferretto, N., Tedetti, M., Guigue, C., Mounier, S., Raimbault, P., Goutx, M., 2017. Spatiotemporal variability of fluorescent dissolved organic matter in the Rhône River delta and the Fos-Marseille marine area (NW Mediterranean Sea, France). Environmental Science and Pollution Research, 24, 4973-4989. 
Gewurtz, S.B., Lazar, R., Haffner, G.D., 2007. Comparison of polycyclic aromatic hydrocarbon and polychlorinated biphenyl dynamics in the benthic invertebrates of lake Erie, USA. Environmental Toxicology and Chemistry 19, 2943-2950.

Ghilardi, M., Psomiadis, D., Cordier, S., Delanghe-Sabatier, D., Demory, F., Hamidi, F., Parashou, T., Dotsika, E., Fouache, E., 2012. The impact of early- to mid-Holocene palaeoenvironmental changes on Neolithic settlement at Nea Nikomideia, Thessaloniki plain, Greece. Quaternary International 266, 47-61.

Grossi, V., Hirschler, A., Raphel, D., Rontani, J-F., De Leeuw, J.W., Bertrand, J-C., 1998. Biotransformation pathways of phytol in recent anoxic sediments. Organic Geochemistry 29, 845-861.

Guigue, C., Tedetti, M., Giorgi, S., Goutx, M., 2011. Occurrence and distribution of hydrocarbons in the surface microlayer and subsurface water from the urban coastal marine area off Marseilles, Northwestern Mediterranean Sea. Marine Pollution Bulletin 62, 27412752.

Guigue, C., Tedetti, M., Ferretto, N., Garcia, N., Méjanelle, L., Goutx, M., 2014. Spatial and seasonal variabilities of dissolved hydrocarbons in surface waters from the Northwestern Mediterranean Sea: Results from one year intensive sampling. Science of the Total Environment 466-467, 650-662.

Guigue, C., Bigot, L., Turquet, J., Tedetti, M., Ferretto, N., Goutx, M., Cuet, P., 2015.Hydrocarbons in a coral reef ecosystem subjected to anthropogenic pressures (La Réunion Island, Indian Ocean). Environmental Chemistry 12, 350-365. 
Guitart, C., García-Flor, N., Dachs, Bayona, J.M., Albaigés, 2004. Evaluation of sampling devices for the determination of polycyclic aromatic hydrocarbons in surface microlayer coastal waters. Marine Pollution Bulletin 48, 961-968.

Gustafsson, O., Gschwend, P.M., Buesseler, K.O., 1997. Using ${ }^{234}$ Th disequilibria to estimate the vertical removal rates of polycyclic aromatic hydrocarbons from the surface ocean. Marine Chemistry 57, 11-23.

Gustafsson, O., Nilsson, N., Bucheli, T.D., 2001. Dynamic colloid-water partitioning of pyrene through a coastal Baltic spring bloom. Environmental Science and Technology 35, 40014006.

Hawthorne, S.B., Azzolina, N.A., Neuhauser, E.F., Kreitinger, J.P., 2007. Predicting Bioavailability of Sediment Polycyclic Aromatic Hydrocarbons to Hyalella azteca using Equilibrium Partitioning, Supercritical Fluid Extraction, and Pore Water Concentrations. Environmental Science and Technology 41, 6297-6304.

He, W., Jung, H., Lee, J.H., Hur, J., 2016. Differences in spectroscopic characteristics between dissolved and particulate organic matters in sediments: Insight into distribution behavior of sediment organic matter. Science of the Total Environment 547, 1-8.

He, Y.Y., Wang, X.C., 2011. Adsorption of a typical polycyclic aromatic hydrocarbon by humic substances in water and the effect of coexisting metal ions. Colloids and Surfaces A: Physicochemical and Engineering Aspects 379, 93-101.

Henrichs, S.M., 1993. Early diagenesis of organic matter: the dynamics (rates) of cycling of organic compounds. In Organic Geochemistry: Principles and Applications. Eds: M.H. Engel, S.A. Macko. Plenum Press New York, pp. 101-114.

Hudson, N., Baker, A., Reynolds, D., 2007. Fluorescence analysis of dissolved organic matter in natural, waste and polluted waters-A review. River Research Applications 23, 631-649. 
Hur, J., Lee, B.-M., Shin, K.-H., 2014. Spectroscopic characterization of dissolved organic matter isolates from sediments and the association with phenanthrene binding affinity. Chemosphere 111, 450-457.

Ishii, S.K.L., Boyer, T.H., 2012. Behavior of Reoccurring PARAFAC Components in Fluorescent Dissolved Organic Matter in Natural and Engineered Systems: A Critical Review. Environmental Science and Technology 46, 2006-2017.

Kaal, J., Wagner, S., Jaffé, R., 2016. Molecular properties of ultrafiltered dissolved organic matter and dissolved black carbon in headwater streams as determined by pyrolysis-GC-MS. Journal of Analytical and Applied Pyrolysis. DOI: 10.1016/j.jaap.2016.02.003

Kahn, S.U., Schnitzer, M., 1972. The retention of hydrophobic organic compounds by humic acid. Geochimica Cosmochimica Acta 36, 745-754.

Katsoyiannis, A., Breivik, K., 2014. Model-based evaluation of the use of polycyclic aromatic hydrocarbons molecular diagnostic ratios as a source identification tool. Environmental Pollution, 184, 488-494.

Karickhoff, S.W., Brown, D.S., Scott, T.A., 1979. Sorption of hydrophobic pollutants on natural sediments.Water Research 13, 241-248.

Karickoff, S.W., Morris, S.W., 1985. Impact of tubificid oligochaetes on pollutant transport in bottm sediments. Environmental Science and Technology 19, 51-56.

Kennish, M.J., 1992. Poly-nuclear aromatic hydrocarbons. Ecology of estuaries: anthropogenic effects. Boca Raton, CRC Press, p. 133-181.

Kim, S.-J., Kwon, J.-H., 2010. Determination of Partition Coefficients for Selected PAHs between Water and Dissolved Organic Matter. Clean - Soil, Air, Water 38, 797-802.

Komada, T., Schofield, O.M.E., Reimers, C.E., 2002. Fluorescence characteristics of organic matter released from coastal sediments during resuspension. Marine Chemistry 79, 81-97. 
Latimer, J.S., Davis, W.R., Keith, D.J., 1999. Mobilization of PAHs and PCBs from in-place contaminated marine sediments during simulated resuspension events. Estuarine, Coastal and Shelf Science 49, 577-595.

Lipiatou, E., Saliot, A., 1991. Fluxes and transport of anthropogenic and natural polycyclic aromatic-hydrocarbons in the western Mediterranean Sea. Marine Chemistry 32, 51-71.

Long, E.R., Macdonald, D.D., Smith, S.L., Calder, F.D., 1995. Incidence of adverse biological effects with ranges of chemical concentrations in marine and estuarine sediments. Environmental Management 19, 81-97.

May, W.E., Wasik, S.P., Freeman, H.F., 1978. Determination of the solubility behavior of some polycyclic aromatic hydrocarbons in water. Analytical Chemistry 50, 997-1000.

McCarthy, J.F., Jimenez, B.D., 1985. Interactions between polycyclic aromatic hydrocarbons and dissolved humic material: Binding and dissociation. Environmental Science and Technology 19, 1072-1076.

Means, J.C., Wood, S.G., Hassett, J.J., Banwart, W.L., 1980. Sorption of polynuclear aromatic hydrocarbons by sediments and soils. Environmental Science and Technology 14, 15241529.

Meyers, P.A., 1994. Preservation of elemental and isotopic source identification of sedimentary organic matter. Chemical Geology 144, 289-302.

Misson, B., Garnier, C., Lauga, B., Dang, D.H., Ghiglione, J.-F., Mullot, J.-U., Duran, R., Pringault, O., 2016. Chemical multi-contamination drives benthic prokaryotic diversity in the anthropized Toulon Bay. Science of The Total Environment 556, 319-329.

Mitra, S., Dellapenna, T.M., Dickut, R.M., 1999. Polycyclic Aromatic Hydrocarbon Distribution within Lower Hudson River Estuarine Sediments: Physical Mixing vs Sediment Geochemistry. Estuarine, Coastal and Shelf Science 49, 311-326. 
Mitra, S., Dickhut, R.M., 1999. Three-phase modeling of polycyclic aromatic hydrocarbon association with pore-water-dissolved organic carbon. Environmental Toxicology and Chemistry 18, 1144-1148.

Muller, P.J., 1977. C/N ratios in Pacific deep-sea sediments: effects of inorganic ammonium and organic nitrogen compounds sorbed by clays. Geochimica Cosmochimica Acta 41, 765-776.

Mzoughi, N., Chouba, L., 2011. Distribution and partitioning of aliphatic hydrocarbons and polycyclic aromatic hydrocarbons between water, suspended particulate matter, and sediment in harbours of the West coastal of the Gulf of Tunis (Tunisia). Journal of Environmental Monitoring 13, 689-698.

Para, J., Coble, P.G., Charrière, B., Tedetti, M., Fontana, C., Sempéré, R., 2010. Fluorescence and absorption properties of chromophoric dissolved organic matter (CDOM) in coastal surface waters of the northwestern Mediterranean Sea, influence of the Rhône River. Biogeosciences, 7, 4083-4103.

Pérez-Fernández, B., Viñas, L., Franco, M.Á., Bargiela, J., 2015. PAHs in the Ría de Arousa (NW Spain): A consideration of PAHs sources and abundance. Marine Pollution Bulletin 95, $155-165$.

Perminova, I.V., Grechishcheva, N.Y., Petrosyan, V.S., 1999. Relationship between Structure and Binding Affinity of Humic Substances for Polycyclic Aromatic Hydrocarbons: Relevance of Molecular Descriptors. Environmental Science and Technology 33, 37813787.

Pougnet, F., Schäfer, J., Dutruch, L., Garnier, C., Tessier, E., Dang, D.H., Lanceleur, L., Mullot, J.-U., Lenoble, V., Blanc, G., 2014. Sources and historical record of tin and butyl-tin species in a Mediterranean bay (Toulon Bay, France). Environmental Science and Pollution Research, 21, 6640-6651. 
Raimbault, P., Diaz, F., Boudjellal, B., 1999. Simultaneous determination of particulate forms of carbon, nitrogen and phosphorus collected on filters using a semiautomatic wet-oxidation procedure. Marine Ecology Progress Series 180, 289-295.

Readman, J.W., Mantoura, R.F.C., Rhead, M.M., 1987. A record of polycyclic aromatic hydrocarbon $(\mathrm{PAH})$ pollution obtained from accreting sediments of the Tamar estuary, U.K.: evidence for non-equilibrium behaviour of PAH. Science of the Total Environment 66, 7394.

Rockne, K.J., Shor, L.M., Young, L.Y., Taghon, G.L., Kosson, D.S., 2002. Distributed Sequestration and Release of PAHs in Weathered Sediment: The Role of Sediment Structure and Organic Carbon Properties. Environmental Science and Technology 36, 2636-2644.

Romera-Castillo, C., Sarmento, H., Alvarez-Salgado, X.A., Gasol, J.M., Marrase, C., 2010. Production of chromophoric dissolved organic matter by marine phytoplankton. Limnology and Oceanography 55, 446-454.

Rontani, J-F., Bonin, P., 2011.Production of pristane and phytane in the marine environment: role of prokaryotes. Research in Microbiology 162, 923-933.

Sabbah, I., Rebhun, M., Gerstl, Z., 2004. An independent prediction of the effect of dissolved organic matter on the transport of polycyclic aromatic hydrocarbons. Journal of Contaminant Hydrology 75, 55-70.

Schoellhamer, D.H., 1996. Anthropogenic sediment resuspension mechanisms in a shallow microtidal estuary. Estuarine, Coastal Shelf Science 43, 533-548.

Sierra, M.M.D., Donard, O.F.X., Etcheber, H., Soriano-Sierra, E.J., Ewald, M., 2001.Fluorescence and DOC contents of pore waters from coastal and deep-sea sediments in the Gulf of Biscay. Organic Geochemistry 32, 1319-1328. 
Sohrin, R., Sempéré, R., 2005. Seasonal variation in total organic carbon in the Northeast Atlantic in 2000-2001. Journal of Geophysical Research 110, C10S90.

Stedmon, C.A., Bro, R., 2008. Characterizing dissolved organic matter fluorescence with parallel factor analysis: a tutorial. Limnology and Oceanography Methods 6, 572-579.

Tedetti, M., Guigue, C., Goutx, M., 2010. Utilization of a submersible UV fluorometer for monitoring anthropogenic inputs in the Mediterranean coastal waters. Marine Pollution Bulletin 60, 350-362.

Tedetti, M., Longhitano, R., Garcia, N., Guigue, C., Ferretto, N., Goutx, M., 2012. Fluorescence properties of dissolved organic matter in coastal Mediterranean waters influenced by a municipal sewage effluent (Bay of Marseilles, France). Environmental Chemistry 9, 438449.

Tedetti, M., Marie, L., Röttgers, R., Rodier, M., Van Wambeke, F., Helias, S., Caffin, M., Cornet-Barthaux, V., Dupouy, C., 2016. Evolution of dissolved and particulate chromophoric materials during the VAHINE mesocosm experiment in the New Caledonian coral lagoon (south-west Pacific). Biogeosciences 13, 3283-3303.

Tessier, E., Garnier, C., Mullot, J-U., Lenoble, V., Arnaud, M., Raynaud, M., Mounier, S., 2011. Study of the spatial and historical distribution of sediment inorganic contamination in the Toulon bay (France). Marine Pollution Bulletin 62, 2075-2086.

Tremblay, L., Kohl, S.D., Rice, J.A., Gagné, J.P., 2005. Effects of temperature, salinity, and dissolved humic substances on the sorption of polycyclic aromatic hydrocarbons to estuarine particles. Marine Chemistry 96, 21-34.

Vane, C.H., Kim A.W., Beriro, D.J., Cave, M.R., Knights K., Moss-Hayes V., Nathanail, P.C., 2014. Polycyclic aromatic hydrocarbons (PAH) and polychlorinated biphenyls (PCB) in urban soil of Greater London, UK. Applied Geochemistry 51, 303-314. 
Van Noort, P.C.M., Cornelissen, G., Ten Hulscher, T.E.M., Vrind, B.A., Rigterink, H., Belfroid, A., 2003. Slow and very slow desorption of organic compounds from sediment: influence of sorbate planarity. Water Research 37, 2317-2322.

Varanasi, U., Reichert, W.L., Stein, J.E., Brown, D.W., Sanborn, H.R., 1985. Bioavailability and biotransformation of aromatic hydrocarbons in benthic organisms exposed to sediment from an urban estuary. Environmental Science and Technology 19, 836-841.

Wang, X-C., Zhang, Y-X, Chen, R.F., 2001. Distribution and Partitioning of Polycyclic Aromatic Hydrocarbons (PAHs) in Different Size Fractions in Sediments from Boston Harbor, United States. Marine Pollution Bulletin 42, 1139-1149.

Woodhead, R.J., Law, R.J., Matthiessen, P., 1999. Polycyclic aromatic hydrocarbons in surface sediments around England and Wales and their possible biological significance. Marine Pollution Bulletin 38, 773-790.

Wafo, E., Abou, L., Nicolay, A., Boissery, P., Perez, T., Ngono Abondo, R., Garnier, C., Chacha, M., Portugal, H., 2016. A chronicle of the changes undergone by a maritime territory, the Bay of Toulon (Var Coast, France), and their consequences on PCB contamination. SpringerPlus 5, 1-14.

Yamashita, Y., Tanoue, E., 2004. In situ production of chromophoric dissolved organic matter in coastal environments. Geophysical Research Letters 31,1-4, doi:10.1029/2004GL019734.

Yang, C., Liu, Y., Zhu, Y., Zhang, Y., 2016. Insights into the binding interactions of autochthonous dissolved organic matter released from Microcystis aeruginosa with pyrene using spectroscopy. Marine Pollution Bulletin 104, 113-120.

Yang, Z., Feng, J., Niu, J., Shen, Z., 2008. Release of polycyclic aromatic hydrocarbons from Yangtze River sediment cores during periods of simulated resuspension. Environmental 
Pollution 155, 366-374.

Yunker, M.B., Macdonald, R.W., Vingarzan, R., Mitchell, R.H., Goyette, D., Sylvestre, S., 2002. PAHs in the Fraser River basin: a critical appraisal of PAH ratios as indicators of PAH source and composition. Organic Geochemistry 33, 489-515.

Zaghden, H., Tedetti, M., Sayadi, S., Serbaji, M.M., Elleuch, B., Saliot, A., 2017. Origin and distribution of hydrocarbons and organic matter in the surficial sediments of the SfaxKerkennah channel (Tunisia, Southern Mediterranean Sea). Marine Pollution Bulletin 117, $414-428$.

Zhou, J.L., Fileman, T.W., Evans, S., Donkin, P., Readman, J.W., Mantoura, R.F.C., Rowland, S., 1999. The partition of fluoranthene and pyrene between suspended particles and dissolved phase in the Humber Estuary: A study of the controlling factors. Science of the Total Environment 243-244, 305-321. 


\section{Figure captions}

Figure 1. Location of the Missiessy (MIS) site in Toulon harbor (Southern France, Northwestern Mediterranean Sea).

Figure 2. Distribution profile of 1) PAHs in the 0-2 and 30-32 cm sediments used for sediment resuspension experiments (SRE) (“0-2 cm sediment” and "30-32 cm sediment”), 2) dissolved PAHs in water samples of SRE performed on the 0-2 cm and 30-32 cm sediments (for each SRE, mean of the eight times: 1, 3, $7 \mathrm{~h}, 1,3,7,10$ and 14 days, with two bottle replicates for each time; $\mathrm{n}=16$ ) ("0-2 cm SRE" and "30-32 cm SRE"), and 3) dissolved PAHs in the water column (mean of the four depths: $0.5,2.5,5$ and $13 \mathrm{~m}$ with two bottle replicates for each depth; $\mathrm{n}=8$ ) ("Water column"). Different letters ( $a, b, c, d$ or $e$ ) are used for significantly different means ( $t$-test, $\mathrm{p}<$ $0.05)$.

Figure 3. Concentrations of dissolved $\Sigma 34$ PAHs $\left(n^{-1} \mathrm{~L}^{-1}\right)(\mathrm{a}, \mathrm{b})$, concentrations in DOC $(\mu \mathrm{M})(\mathrm{c}$, d), and fluorescence intensities of humic-like (e, f) and tryptophan-like (g, h) fluorophores (QSU) in water during the 0-2 cm (white dots) and 30-32 cm (gray dots) sediment resuspension experiments (SRE). Polynomial functions of degree 3 (cubic functions) obtained by least square fits are shown as black lines along with their respective equation and correlation coefficient. The dotted line represents the concentration in the water before sediment addition for each parameter. The standard deviation is given for the two bottle replicates $(n=2)$. For DOC, the sample at day 7 for 30-32 cm SRE, considered as an outlier, was removed. 
Figure 4. Relationship between $\log \mathrm{K}_{\mathrm{ow}}$ and $\log \mathrm{K}_{\mathrm{oc}}$ determined during the sediment resuspension experiments performed on the $0-2 \mathrm{~cm}$ (white dots for 2-4 ring compounds, white square for 5-6 ring ones) and 30-32 cm (gray dots for 2-4 ring compounds, gray square for 5-6 ring ones) sediments for the 16 priority PAHs. The equations for 2-4 ring and 5-6 ring compounds in the $0-2 \mathrm{~cm}$ SRE were $\mathrm{y}=0.59 \mathrm{x}+4.9(\mathrm{r}=0.89, \mathrm{n}=10, \mathrm{p}<0.05)$ and $\mathrm{y}=0.07 \mathrm{x}+$ $7.3(\mathrm{r}=0.12, \mathrm{n}=6, \mathrm{p}>0.05)$, respectively. The equations related to $2-4$ ring and 5-6 ring compounds in the 30-32 cm SRE were $y=0.64 x+4.7(r=0.91, n=10, p<0.05)$ and $y=-0.17 x$ $+8.7(\mathrm{r}=0.24, \mathrm{n}=6, \mathrm{p}>0.05)$, respectively. Crosses represent the theoretical relationship log $\mathrm{K}_{\mathrm{oc}}=\log \mathrm{K}_{\mathrm{ow}}-0.32$ according to Means et al. (1980). Black diamonds represent values from Bouloubassi and Saliot(1992). The standard deviation of $\log \mathrm{K}_{\mathrm{oc}}$ for each compound is given for the two bottle replicates $(n=2)$. The $\log K_{\text {ow }}$ are the means of different values reported in Accardi-Dey and Gschwend (2003); Dong et al. (2015); Feng et al. (2007); Socha and Carpenter (1987). 
Table 1. Concentration range of the 16 priority PAHs $\left(10^{3} \mathrm{ng} \mathrm{g}^{-1}\right.$ sed. $\left.\mathrm{dw}\right)$ in the whole sediment core and in the 0-2 and 30-32 $\mathrm{cm}$ sediments used for sediment resuspension experiments (SRE). Comparison with the toxicity critical levels published in JORF for the French legislation and with the international SQG references proposed by Long et al. (1995).

\begin{tabular}{|c|c|c|c|c|c|c|c|}
\hline \multirow[t]{2}{*}{ Compound } & \multirow[t]{2}{*}{ Whole core } & \multirow[t]{2}{*}{$0-2 \mathrm{~cm}$ deep } & \multirow[t]{2}{*}{$30-32 \mathrm{~cm}$ deep } & \multicolumn{2}{|c|}{ JORF (fraction $<2 \mathrm{~mm}$ ) } & \multicolumn{2}{|c|}{ SQG (Long et al., 1995) } \\
\hline & & & & L1 & L2 & ERL & ERM \\
\hline Naph & $0.161-1.22$ & 0.526 & 0.585 & 0.160 & 1.13 & 0.160 & 2.10 \\
\hline Acy & $0.102-1.01$ & 0.179 & 0.247 & 0.040 & 0.340 & 0.044 & 0.640 \\
\hline Ace & $0.233-2.38$ & 0.769 & 0.468 & 0.015 & 0.260 & 0.016 & 0.500 \\
\hline Flu & $0.287-2.45$ & 0.484 & 0.383 & 0.020 & 0.280 & 0.019 & 0.540 \\
\hline Phe & $2.37-24.6$ & 2.98 & 2.96 & 0.240 & 0.870 & 0.240 & 1.50 \\
\hline Ant & $0.526-3.75$ & 0.588 & 0.634 & 0.085 & 0.590 & 0.085 & 1.10 \\
\hline Flt & $3.22-46.6$ & 4.38 & 4.41 & 0.600 & 2.85 & 0.600 & 5.10 \\
\hline Pyr & $2.78-36.1$ & 3.41 & 3.70 & 0.500 & 1.50 & 0.665 & 2.60 \\
\hline $\mathrm{BaA}$ & $0.988-11.3$ & 1.83 & 1.39 & 0.260 & 0.930 & 0.261 & 1.60 \\
\hline Chr & $0.988-10.1$ & 1.78 & 1.43 & 0.380 & 1.59 & 0.384 & 2.80 \\
\hline $\mathrm{BbF}$ & $2.020-13.8$ & 3.42 & 2.84 & 0.400 & 0.900 & & \\
\hline $\mathrm{BkF}$ & $0.601-4.30$ & 0.912 & 0.878 & 0.200 & 0.400 & & \\
\hline $\mathrm{BaP}$ & $1.15-9.12$ & 2.13 & 1.71 & 0.430 & 1.02 & 0.430 & 1.60 \\
\hline IndP & $1.50-7.48$ & 2.71 & 1.99 & 1.70 & 5.65 & & \\
\hline DBA & $0.331-2.09$ & 0.553 & 0.452 & 0.060 & 0.160 & 0.063 & 0.260 \\
\hline BP & $1.05-6.47$ & 1.89 & 1.77 & 1.70 & 5.65 & & \\
\hline$\Sigma 16$ PAHs & $22.9-182$ & 28.5 & 25.8 & & & & \\
\hline ¿34 PAHs & $30.7-231$ & 38.2 & 35.7 & & & & \\
\hline
\end{tabular}

JORF: French Republic Official Journal; SQG: sediment quality guidelines. L1 and L2: critical levels 1 and 2; ERL and ERM: effects rangelow and effects range-median. 
Table 2. Physical and chemical characteristics of the 0-2 and 30-32 $\mathrm{cm}$ sediments used for sediment resuspension experiments (SRE).

\begin{tabular}{lll}
\hline & $0-2 \mathrm{~cm}$ sediment & $30-32 \mathrm{~cm}$ sediment \\
\cline { 2 - 3 } Moisture (\%) & 62 & 52 \\
Sand (\%) & 0 & 0 \\
Silt (\%) & 69 & 82 \\
Clay (\%) & 31 & 18 \\
OC $(\%)$ & 8.2 & 6.3 \\
ON $(\%)$ & 0.61 & 0.29 \\
$\mathrm{C} / \mathrm{N}$ & 13.5 & 22.0 \\
$\Sigma 34 \mathrm{PAHs}\left(10^{3} \mathrm{ng} \mathrm{g}^{-1}\right)$ & 38.2 & 35.7 \\
$R\left(10^{3} \mathrm{ng} \mathrm{g}^{-1}\right)$ & 2.41 & 10.0 \\
$\mathrm{UCM} / R$ & 30 & 118 \\
$\mathrm{CPI}_{15-24}$ & 1.3 & 1.3 \\
$\mathrm{CPI}_{25-36}$ & 2.9 & 2.2 \\
\hline $\mathrm{OC}^{2}$ & &
\end{tabular}

OC and ON: organic carbon and nitrogen (\% for $1 \mathrm{~g}$ sed. dw); $\Sigma 34$ PAHs: concentrations in total polycyclic aromatic hydrocarbons $\left(10^{3} \mathrm{ng} \mathrm{g}^{-1}\right.$ sed. $\mathrm{dw}) ; R$ : concentration in resolved $n$-alkanes from $n$ - $\mathrm{C}_{15}$ to $n$ - $\mathrm{C}_{36}$ with two isoprenoids, pristane (Pr) and phytane (Phy) $\left(10^{3} \mathrm{ng} \mathrm{g}^{-1}\right.$ sed. dw); UCM: unresolved complex mixture. $\mathrm{CPI}_{15-24}$ and $\mathrm{CPI}_{25-36}$ : carbon preference indices in the ranges $n-\mathrm{C}_{15}-n-\mathrm{C}_{24}$ and $n-\mathrm{C}_{25}-n-\mathrm{C}_{36}$. 
Table 3. Pearson's correlation matrices for the concentrations of dissolved $\Sigma 34$ PAHs and dissolved organic matter (DOM) during sediment resuspension experiments (SRE) conducted on the $0-2$ and $30-32 \mathrm{~cm}$ sediments. Significant linear correlations $(p<0.05)$ are in bold.

a) 0-2 cm $\operatorname{SRE}(\mathrm{n}=8)$

\begin{tabular}{llll}
\hline Variables & $\Sigma 34$ PAHs & DOC & Humic \\
\hline DOC & -0.03 & & \\
Humic & 0.69 & 0.39 & \\
Tryptophan & 0.56 & 0.43 & $\mathbf{0 . 9 8}$ \\
\hline
\end{tabular}

b) $30-32 \mathrm{~cm} \mathrm{SRE}(\mathrm{n}=7$ or 8$)$

\begin{tabular}{llll}
\hline Variables & $\Sigma 34$ PAHs & DOC & Humic \\
\hline DOC & 0.50 & & \\
Humic & $\mathbf{0 . 7 5}$ & 0.66 & \\
Tryptophan & 0.54 & $\mathbf{0 . 7 8}$ & $\mathbf{0 . 9 2}$ \\
\hline
\end{tabular}

PAHs: polycyclic aromatic hydrocarbons; DOC: dissolved organic carbon; Humic and tryptophan: Humic- and tryptophan-like fluorophores of fluorescent dissolved organic matter (FDOM).

Table 4. Concentration ranges of the 16 priority PAHs in water (ng L ${ }^{1}$ ) during sediment resuspension experiments (SRE) performed on the 
0-2 and 30-32 cm sediments. Comparison with the MAC-EQS of the EU Water Framework Directive (WFD, 2013/39/EU).

\begin{tabular}{|c|c|c|c|}
\hline Compound & $0-2 \mathrm{~cm} \mathrm{SRE}$ & $30-32 \mathrm{~cm} \mathrm{SRE}$ & MAC-EQS \\
\hline Naph & $0.3-1.7$ & $0.6-2.7$ & 130000 \\
\hline Acy & $0.1-0.2$ & $0.1-1.9$ & \\
\hline Ace & $0.3-0.8$ & $0.5-3.1$ & \\
\hline Flu & $0.3-1.6$ & $0.4-2.9$ & \\
\hline Phe & $0.5-2.2$ & $0.6-4.5$ & \\
\hline Ant & $b d l-0.7$ & $b d l-1.7$ & 100 \\
\hline Flt & $0.2-3.9$ & $0.3-3.3$ & 120 \\
\hline Pyr & $0.8-4.8$ & $0.2-2.9$ & \\
\hline $\mathrm{BaA}$ & $b d l-0.2$ & $b d l-0.6$ & \\
\hline Chr & $0.1-3.4$ & $b d l-2.2$ & \\
\hline $\mathrm{BbF}$ & $0.6-2.6$ & $0.7-3.7$ & 17 \\
\hline $\mathrm{BkF}$ & $0.2-1.3$ & $b d l-1.9$ & 17 \\
\hline $\mathrm{BaP}$ & $0.1-1.6$ & $b d l-2.5$ & 27 \\
\hline IndP & $b d l-2.0$ & $b d l-2.1$ & \\
\hline DBA & $b d l-0.4$ & $b d l-1.0$ & \\
\hline BP & $0.2-3.1$ & $b d l-4.2$ & 0.82 \\
\hline
\end{tabular}

MAC-EQS: Maximum allowable concentration-environmental quality standards in water for a particular event/forcing; $b d l$ : below detection limit. 


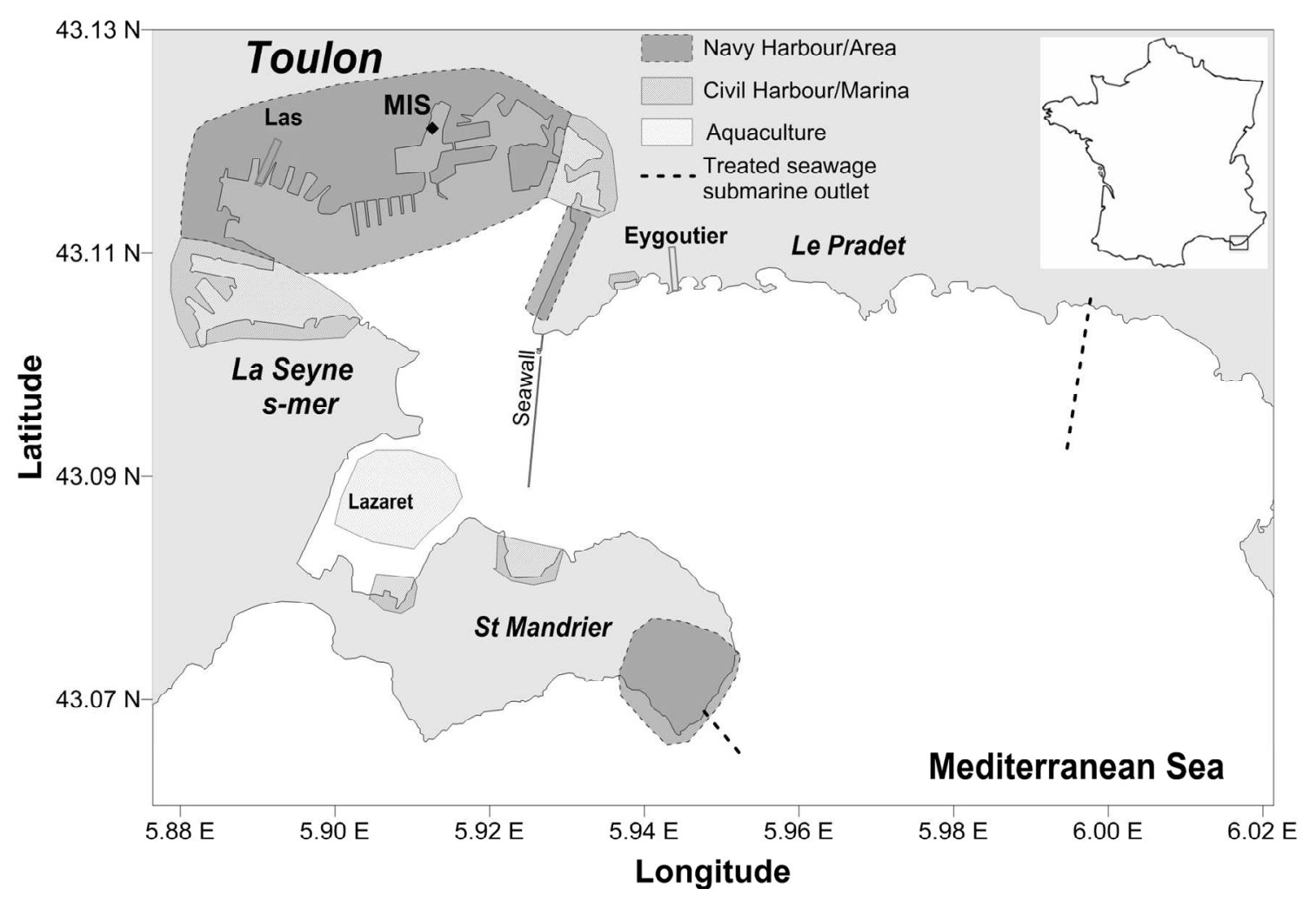

Figure 1 


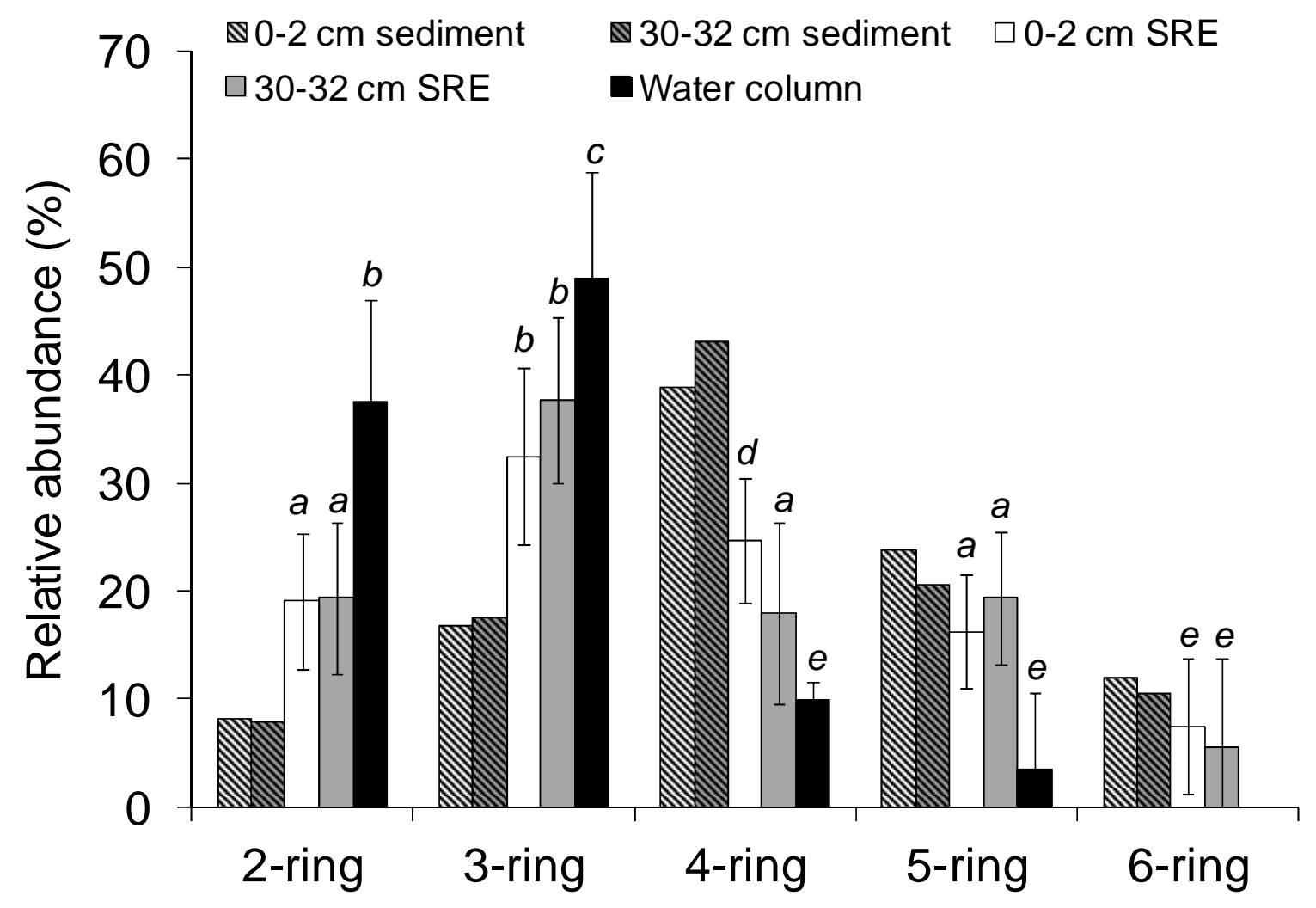

Figure 2 


\section{O0-2 cm SRE $\quad 030-32 \mathrm{~cm}$ SRE}
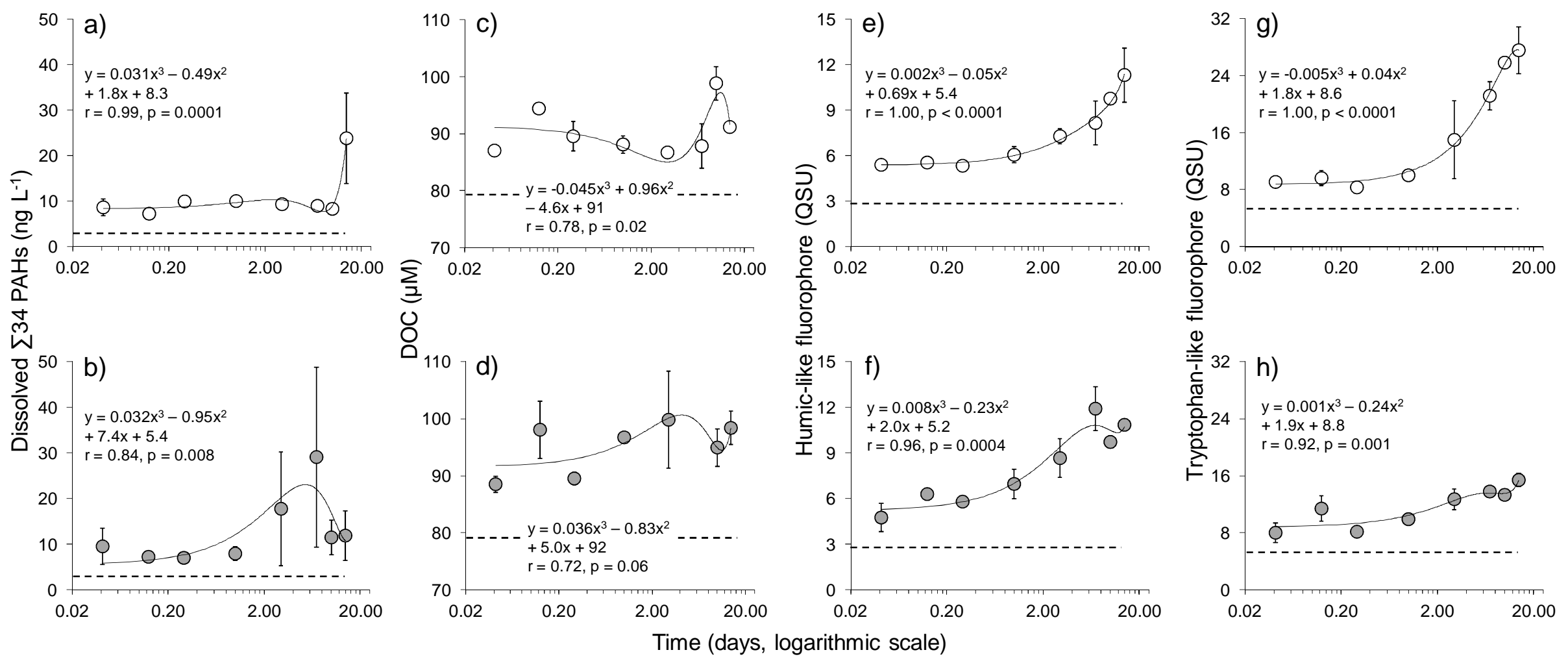

Figure 3 


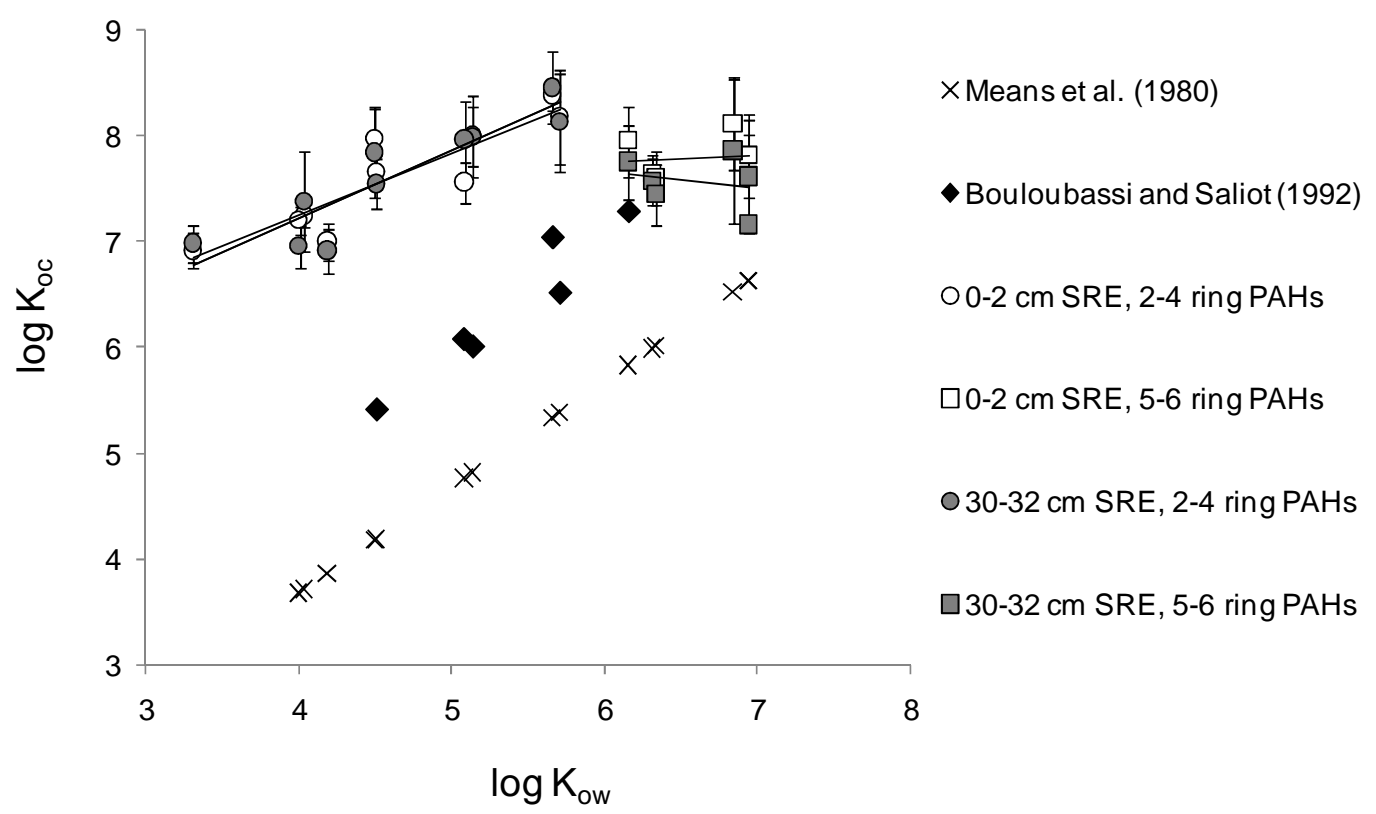

Figure 4 
Remobilization of polycyclic aromatic hydrocarbons and organic matter in seawater during sediment resuspension experiments from a polluted coastal environment: insights from Toulon Bay (France)

Catherine Guigue $^{\mathrm{a},{ }^{*}}$, Marc Tedetti ${ }^{\mathrm{a}}$, Duc Huy Dang ${ }^{\mathrm{b} 2}$, Jean-Ulrich Mullot ${ }^{\mathrm{c}}$, Cédric Garnier $^{\mathrm{b}}$, Madeleine Goutx ${ }^{\mathrm{a}}$

${ }^{a}$ Aix Marseille Université, CNRS/INSU, Université de Toulon, IRD, Mediterranean Institute of Oceanography (MIO) UM 110, 13288, Marseille, France

${ }^{\text {b }}$ Laboratoire PROTEE, EA 3819, Université de Toulon, BP 20132, 83957 La Garde, France

${ }^{\mathrm{c}}$ LASEM-Toulon, Base Navale de Toulon, BP 61, 83800 Toulon, France

*Corresponding author: catherine.guigue@mio.osupytheas.fr; Phone: +33(0)4 860905 25; Fax: +33(0)491829641

\section{Supplementary material}

\footnotetext{
${ }^{2}$ Present address: School of the Environment, Trent University, 1600 West Bank Drive, Peterborough, ON, K9L 0G2, Canada
} 


\section{Text S1. Determination of hydrocarbons}

Concerning PAHs, measured compounds are namely naphthalene (Naph), acenaphthylene (Acy), acenaphtene (Ace), fluorene (Flu), dibenzothiophene (DBT), phenanthrene (Phe), anthracene (Ant), fluoranthene (Flt), pyrene (Pyr), benz[a]anthracene (BaA), chrysene $(\mathrm{Chr})$, benzo[b]fluoranthene $(\mathrm{BbF})$, benzo[k]fluoranthene $(\mathrm{BkF})$, benzo $[e]$ pyrene $(\mathrm{BeP})$, benzo[ $[a]$ pyrene $(\mathrm{BaP})$, perylene (Per), dibenz $[a, h]$ anthracene (DBA), benzo $[g, h, i]$ perylene (BP), indeno[1,2,3-cd]pyrene (IndP). The isomeric ratios (Ant/Ant+Phe, $\mathrm{BaA} / \mathrm{BaA}+\mathrm{Chr}$, IndP/IndP+BP and Flt/Flt+Pyr) were used to assess the origin of the sediment particles (Tobiszewski and Namieśnik, 2012; Yunker et al., 2002).

Concerning AHs, the UCM hump corresponds to a mixture of many structurally complex isomers and homologues of branched and cyclic hydrocarbons that cannot be resolved by capillary GC columns (Bouloubassi and Saliot, 1993). Its relative importance, expressed as the ratio of unresolved to resolved compounds ( $\mathrm{UCM} / R)$, is commonly used as a diagnostic criterion of petroleum inputs (Mazurek and Simoneit, 1984). We also determined the carbon preference indices in the ranges $n-\mathrm{C}_{15}-n-\mathrm{C}_{24}$ and $n-\mathrm{C}_{25}-n-\mathrm{C}_{36}\left(\mathrm{CPI}_{15-24}\right.$ and $\mathrm{CPI}_{25-36}$, respectively), expressed as the ratio of odd to even carbon numbered $n$-alkanes (Blumer et al., 1971; Bouloubassi and Saliot, 1993; Douglas and Eglinton, 1966). Finally, we also assessed the relative proportions of biogenic (marine and terrigenous) and petroleum $n$-alkanes using the formula: $\%$ anthropogenic $n$-alkanes $=2 /(\mathrm{CPI}+1) \times 100$

\section{Text S2. Environmental quality guidelines}

For the present study, the PAH concentrations were compared either to the (i) "Official Journal of the French Republic" (JORF), number 0046, February $23^{\text {th }} 2013$ as current local legislation and to (ii) the "sediment quality guidelines" (SQG) proposed by Long et al. (1995) as international reference (Barhoumi et al., 2014; Guo et al., 2007; Zaghden et al., 2017). They both proposed two critical levels: the levels 1 and 2 for JORF (L1 and L2, respectively) 
and the effect range-low (ERL) and effect range-median (ERM) for SQG. The two low levels (L1 and ERL), when exist, are very close to each other, whereas ERM are almost the double of L2 (Table 1). Briefly, the concentrations below L1 and ERL values reflect no particular contamination or conditions in which biologically adverse effects would be rarely observed. The concentrations between L1 and L2 or ERL and ERM values represent a potential contamination with adverse effects occasionally occurring and imply complementary investigations. The concentrations equal or above L2 or ERM values represent a high contamination with adverse effects frequently occurring. For waters, the PAH concentrations were compared to the maximum allowable concentration for environmental quality standards (MAC-EQS) defined by the European Union Water Framework Directive (WFD, 2013/39/EU). 
Table S1. Chemical characteristics of porewaters of the 0-2 and 30-

$32 \mathrm{~cm}$ sediments used for sediment resuspension experiments.

\begin{tabular}{|c|c|c|}
\hline & $0-2 \mathrm{~cm}$ sediment & $30-32 \mathrm{~cm}$ sediment \\
\hline $\mathrm{pH}$ & 7.49 & 7.51 \\
\hline $\mathrm{Eh}(\mathrm{mV} / \mathrm{ENH})$ & 109 & -145 \\
\hline $\mathrm{DOC}(\mu \mathrm{M})$ & $367 \pm 8$ & $717 \pm 8$ \\
\hline $\mathrm{DIC}(\mathrm{mM})$ & $2.81 \pm 0.02$ & $2.78 \pm 0.03$ \\
\hline $\mathrm{N}_{\mathrm{T}}(\mu \mathrm{M})$ & $104 \pm 2$ & $173 \pm 8$ \\
\hline $\mathrm{NH}_{4}^{+}(\mu \mathrm{M})$ & 72.6 & 54.8 \\
\hline $\mathrm{SRP}(\mu \mathrm{M})$ & 7.1 & 5.1 \\
\hline $\mathrm{Si}(\mathrm{OH})_{4}(\mu \mathrm{M})$ & 95.4 & 110.2 \\
\hline $\mathrm{Mn}_{\mathrm{T}}(\mathrm{nM})$ & 2.3 & 0.7 \\
\hline $\mathrm{Fe}(\mathrm{II})=\mathrm{Fe}_{\mathrm{T}}(\mu \mathrm{M})$ & 70.2 & 7.7 \\
\hline $\mathrm{SO}_{4}^{2-}(\mathrm{mM})$ & 30.7 & 28.8 \\
\hline$\Sigma \mathrm{HS}^{-}(\mu \mathrm{M})$ & $<0.3$ & $<0.3$ \\
\hline
\end{tabular}


Table S2. Partition coefficients of the individual PAHs between sediment and water ( $\left.\log \mathrm{K}_{\mathrm{d}}\right)$ and between sediment organic matter and water $\left(\log \mathrm{K}_{\mathrm{oc}}\right.$ ) determined in this study during sediment resuspension experiments (SRE). Comparison with the $\log \mathrm{K}_{\mathrm{d}}$, $\log \mathrm{K}_{\mathrm{oc}}$ and partition coefficients between octanol and water $\left(\log \mathrm{K}_{\mathrm{ow}}\right)$ from the literature. The $\log \mathrm{K}_{\mathrm{ow}}$ are the means of different values reported in Accardi-Dey and Gschwend (2003); Dong et al. (2015); Feng et al. (2007); Socha and Carpenter (1987).

\begin{tabular}{|c|c|c|c|c|c|c|c|c|c|c|c|c|c|c|c|c|c|}
\hline $\log K_{o w}$ & & $\begin{array}{l}\text { Naph } \\
3.31\end{array}$ & & $\begin{array}{l}\text { Acy } \\
4.04\end{array}$ & & $\begin{array}{l}\text { Ace } \\
4.00\end{array}$ & & $\begin{array}{l}\text { Flu } \\
4.19\end{array}$ & & $\begin{array}{l}\text { Phe } \\
4.51\end{array}$ & & $\begin{array}{l}\text { Ant } \\
4.50\end{array}$ & & $\begin{array}{l}\text { Flt } \\
5.14\end{array}$ & & $\begin{array}{l}\mathbf{P y r} \\
5.09\end{array}$ & \\
\hline & $\%$ & $\log$ & $\log$ & $\log$ & $\log$ & $\log$ & $\log$ & $\log$ & $\log$ & $\log$ & $\log$ & $\log$ & $\log$ & $\log$ & $\log$ & $\log$ & $\log$ \\
\hline & $\mathrm{OC}$ & $\mathrm{K}_{\mathrm{d}}$ & $\mathrm{K}_{\mathrm{oc}}$ & $\mathrm{K}_{\mathrm{d}}$ & $\mathrm{K}_{\mathrm{oc}}$ & $\mathrm{K}_{\mathrm{d}}$ & $\mathrm{K}_{\mathrm{oc}}$ & $\mathrm{K}_{\mathrm{d}}$ & $\mathrm{K}_{\mathrm{oc}}$ & $\mathrm{K}_{\mathrm{d}}$ & $\mathrm{K}_{\mathrm{oc}}$ & $\mathrm{K}_{\mathrm{d}}$ & $\mathrm{K}_{\mathrm{oc}}$ & $\mathrm{K}_{\mathrm{d}}$ & $\mathrm{K}_{\mathrm{oc}}$ & $\mathrm{K}_{\mathrm{d}}$ & $\mathrm{K}_{\mathrm{oc}}$ \\
\hline This study & $6.3-8.2$ & 5.8 & $6.9-7.0$ & 6.2 & 7.3-7.4 & $5.8-6.1$ & $7.0-7.2$ & $5.7-5.9$ & $6.9-7.0$ & $6.3-6.6$ & $7.5-7.7$ & $6.6-6.9$ & $7.8-8.0$ & $6.8-6.9$ & 8.0 & $6.5-6.8$ & $7.6-8.0$ \\
\hline $\begin{array}{l}\text { Accardy-Dey and } \\
\text { Gschwend (2002) }\end{array}$ & $1.2-3.1$ & & & & & & & & & & & & & & & $3.5-3.7$ & 5.3 \\
\hline $\begin{array}{l}\text { Accardy-Dey and } \\
\text { Gschwend (2003) }\end{array}$ & & & & & & & & & & & & & & & & $3.9-5.6$ & \\
\hline Cornelissen et al. (2006) & $1.7-7.4$ & & & & & & & & & & $6.0-6.2$ & & & & $5.8-6.4$ & & $5.9-6.3$ \\
\hline Dong et al. (2015) & $0.9-4.8$ & & $4.0-4.9$ & & $5.2-5.7$ & & $4.8-5.4$ & & $5.0-5.7$ & & $5.3-6.1$ & & $4.7-5.7$ & & $5.2-6.2$ & & $4.5-6.4$ \\
\hline $\begin{array}{l}\text { Feng et al. (2007) } \\
\text { Jonker and Koelmans } \\
(2001)\end{array}$ & $1.1-6.3$ & & & & & $2.7-3.2$ & & $2.2-2.9$ & & $2.5-3.1$ & 5.7 & 2.4 & & $3.1-3.3$ & & $3.2-3.7$ & 6.1 \\
\hline Latimer et al. (1999) & $2.5-5.6$ & $2.0-3.4$ & & $2.3-4.6$ & & $2.6-4.4$ & & & & $3.9-6.2$ & & $3.9-4.1$ & & $4.3-5.3$ & & $4.3-5.0$ & \\
\hline Mitra et al. (1999a) & & & & & & & $3.6-6.1$ & & & & & & & & & & $3.1-6.5$ \\
\hline Mitra et al. (1999b) & $1.5-4.5$ & & & & & & & & & & & & & & & & $5.1-5.4$ \\
\hline $\begin{array}{l}\text { Socha and Carpenter } \\
\text { (1987) }\end{array}$ & $0.4-2.7$ & & & & & & & & & & 5.0 & & & & 4.5 & & 5.1 \\
\hline & & $\mathbf{B a A}$ & & Chr & & $\mathbf{B b F}$ & & BkF & & BaP & & IndP & & DBA & & $\mathbf{B P}$ & \\
\hline $\log K_{o w}$ & & 5.66 & & 5.71 & & 6.31 & & 6.34 & & 6.15 & & 6.84 & & 6.94 & & 6.94 & \\
\hline & $\%$ & $\log$ & $\log$ & $\log$ & $\log$ & $\log$ & $\log$ & $\log$ & $\log$ & $\log$ & $\log$ & $\log$ & $\log$ & $\log$ & $\log$ & $\log$ & $\log$ \\
\hline & OC & $\mathrm{K}_{\mathrm{d}}$ & $\mathrm{K}_{\mathrm{oc}}$ & $\mathrm{K}_{\mathrm{d}}$ & $\mathrm{K}_{\mathrm{oc}}$ & $\mathrm{K}_{\mathrm{d}}$ & $\mathrm{K}_{\mathrm{oc}}$ & $\mathrm{K}_{\mathrm{d}}$ & $\mathrm{K}_{\mathrm{oc}}$ & $\mathrm{K}_{\mathrm{d}}$ & $\mathrm{K}_{\mathrm{oc}}$ & $\mathrm{K}_{\mathrm{d}}$ & $\mathrm{K}_{\mathrm{oc}}$ & $\mathrm{K}_{\mathrm{d}}$ & $\mathrm{K}_{\mathrm{oc}}$ & $\mathrm{K}_{\mathrm{d}}$ & $\mathrm{K}_{\mathrm{oc}}$ \\
\hline This study & $6.3-8.2$ & 7.3 & $8.4-8.5$ & $6.9-7.1$ & $8.1-8.2$ & $6.4-6.6$ & 7.6 & $6.2-6.5$ & $7.4-7.6$ & $6.6-6.9$ & $7.8-8.0$ & $6.6-7.0$ & $7.9-8.1$ & $6.0-6.5$ & $7.2-7.6$ & $6.4-6.7$ & $7.6-7.8$ \\
\hline Cornelissen et al. (2006) & $1.7-7.4$ & & & & $6.9-7.5$ & & $6.9-7.3$ & & & & $6.8-7.5$ & & $7.3-8.1$ & & & & $7.6-8.1$ \\
\hline Dong et al. (2015) & $0.9-4.8$ & & $5.4-6.4$ & & $5.1-6.0$ & & & & & & & & & & & & \\
\hline Latimer et al. (1999) & $2.5-5.6$ & $4.2-4.9$ & & $4.3-4.9$ & & $4.1-4.6$ & & $4.0-5.5$ & & $4.6-5.2$ & & $3.6-4.8$ & & $2.3-4.0$ & & $3.7-4.9$ & \\
\hline $\begin{array}{l}\text { Jonker and Koelmans } \\
\text { (2001) }\end{array}$ & & & & & & & & & & & 7.96 & & & & & & 7.84 \\
\hline Lohman et al. (2005) & & & & & & & & & & & $7.0-7.5$ & & & & & & \\
\hline Mitra et al. (1999a) & & & & & & & $4.1-7.1$ & & & & $2.7-7.0$ & & $4.0-7.0$ & & $2.5-6.6$ & & \\
\hline Mitra et al. (1999b) & $1.5-4.5$ & & & & & & $5.1-6.0$ & & $5.1-6.0$ & & $5.4-6.2$ & & & & & & $5.1-6.0$ \\
\hline $\begin{array}{l}\text { Socha and Carpenter } \\
\text { (1987) }\end{array}$ & $0.4-2.7$ & & 5.5 & & 5.5 & & 5.8 & & 5.8 & & 5.9 & & & & & & 6.4 \\
\hline
\end{tabular}




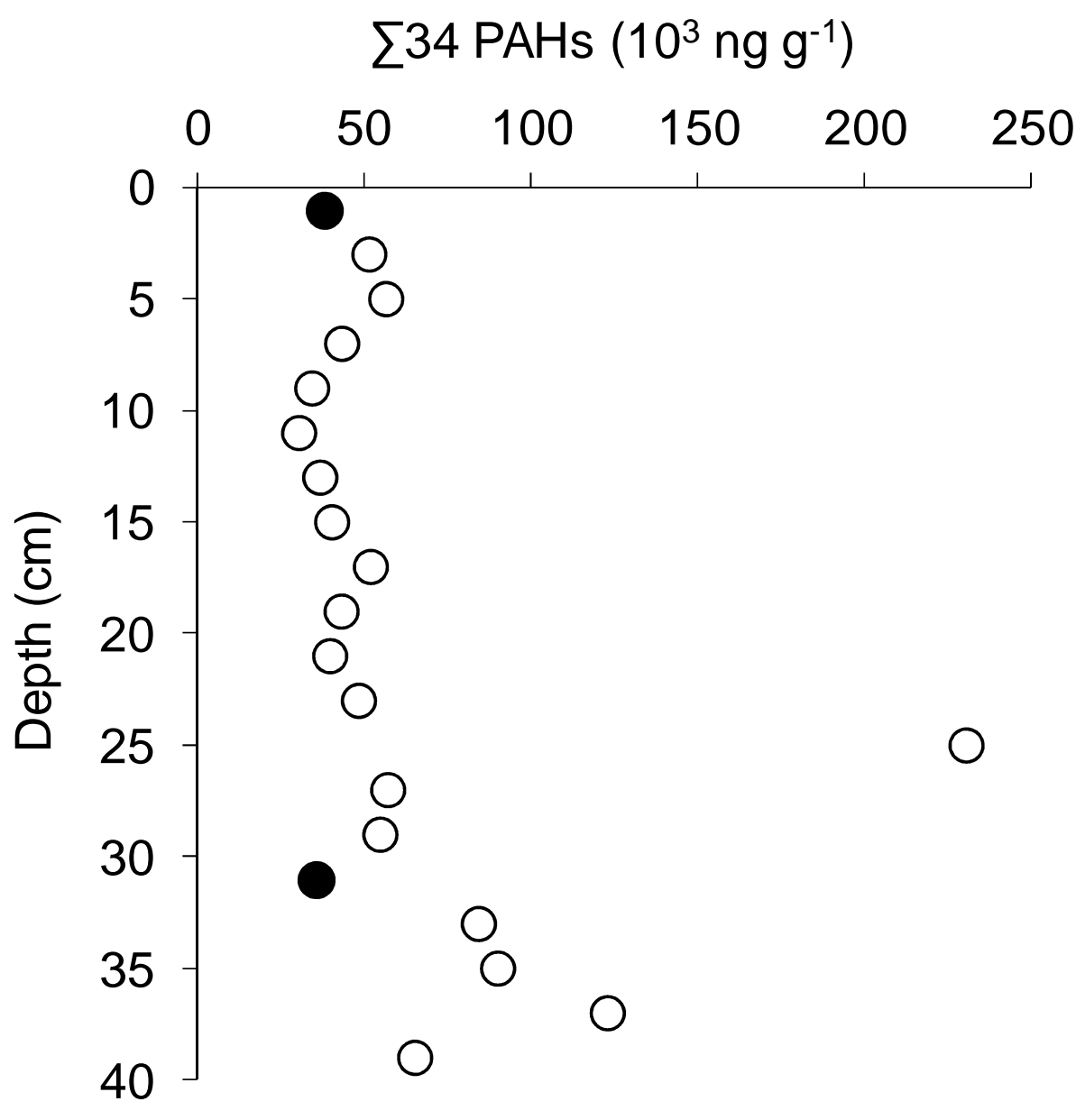

Figure S1. Concentrations of $\Sigma 34$ PAHs $\left(10^{3} \mathrm{ng} \mathrm{g}^{-1}\right.$ sed. dw) with depth in the whole sediment core from the MIS site. The black circles represent the 0-2 and 30-32 cm sediment samples used for sediment resuspension experiments (SRE). 

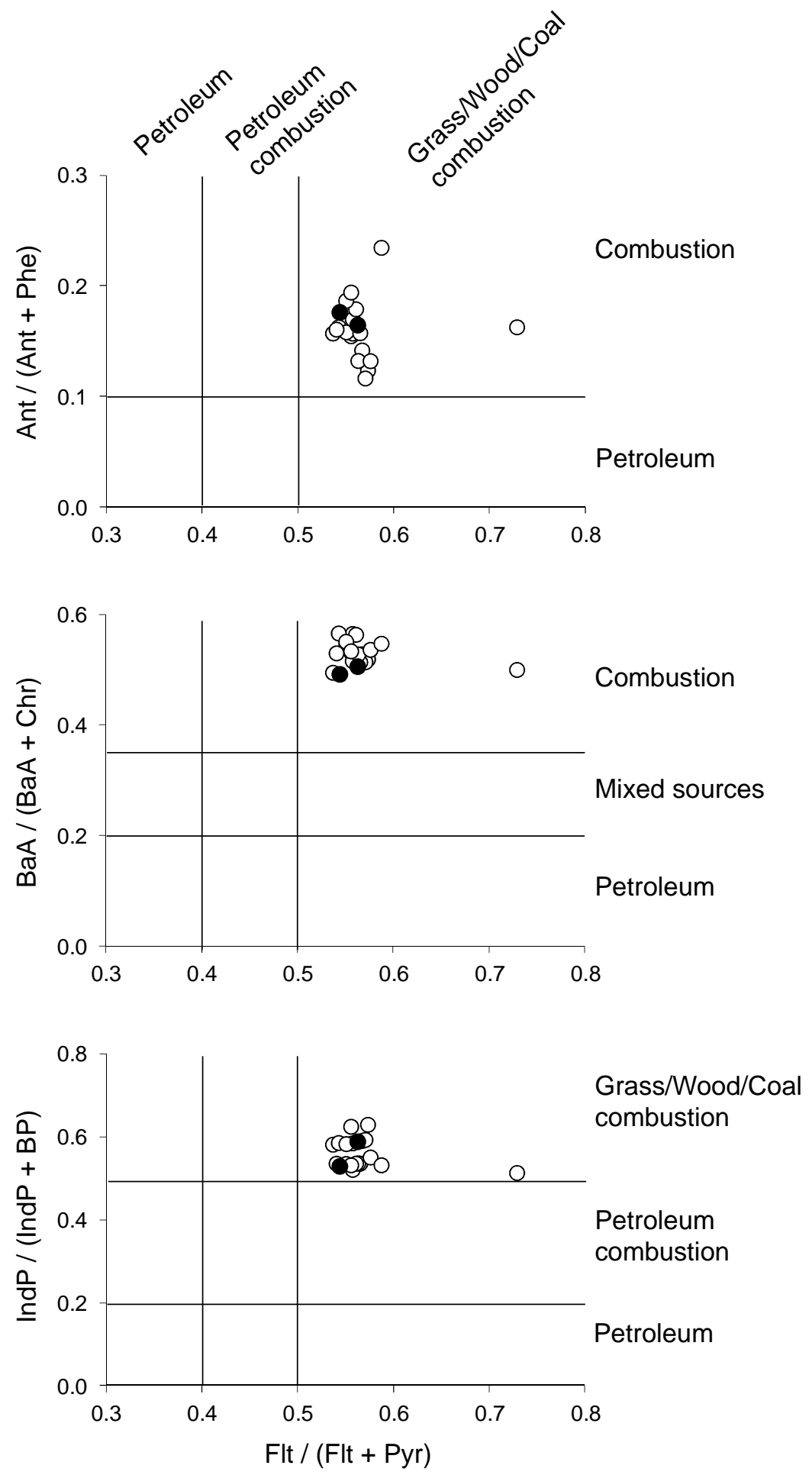

Figure S2. Cross plots of PAH isomeric ratios for the whole sediment core from the MIS site. The black circles represent the 0-2 and 30-32 cm sediment samples used for sediment resuspension experiments (SRE). 


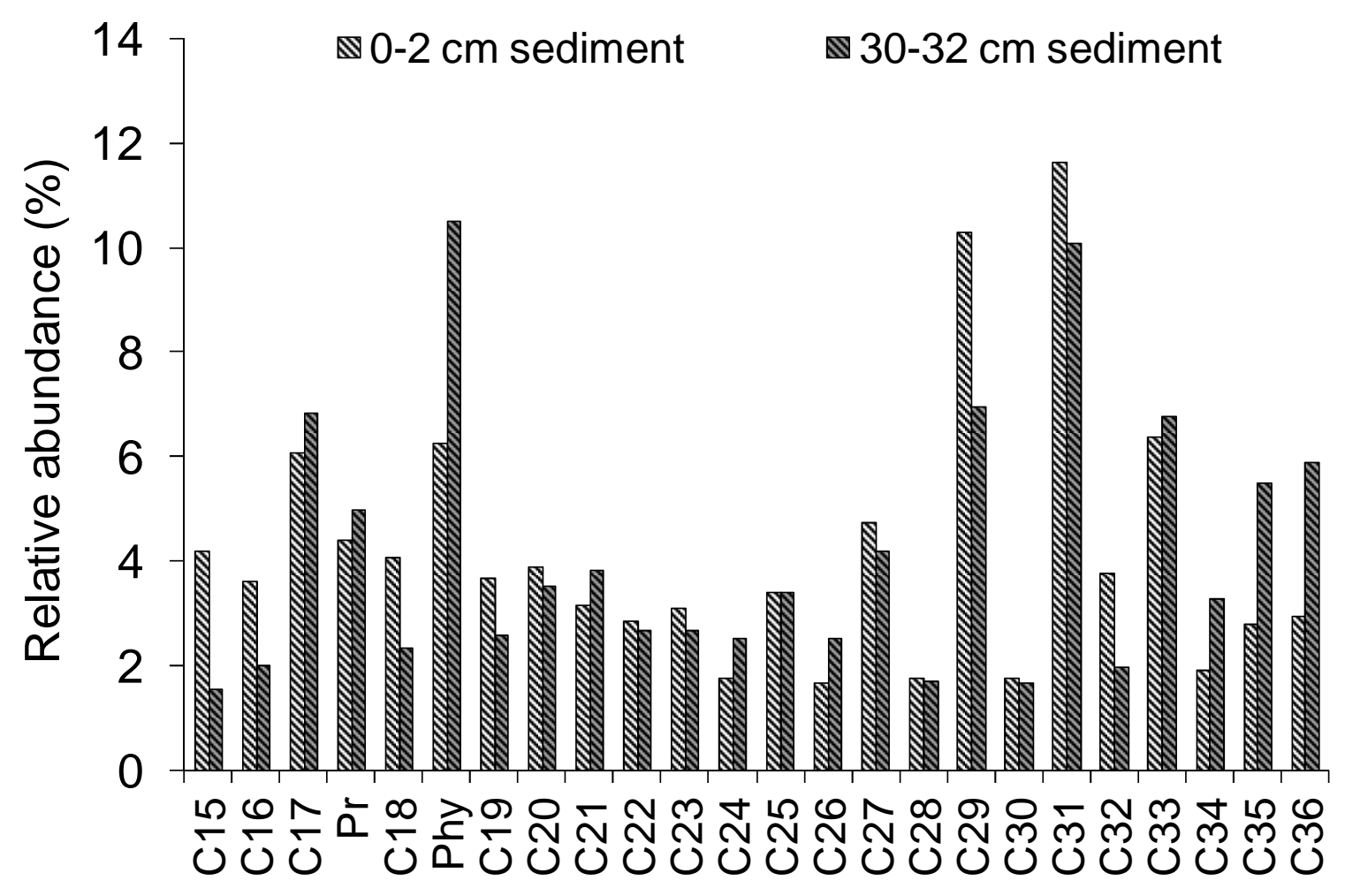

Figure S3. Molecular distribution profile (\%) of resolved $n$-alkanes with pristane (Pr) and phytane (Phy) for the 0-2 and 30-32 cm sediments used for sediment resuspension experiments (SRE). 
a) Dissolved $\sum 34 \mathrm{PAHs}\left(\mathrm{ng} \mathrm{L}^{-1}\right)$
b) $\mathrm{DOC}(\mu \mathrm{M})$
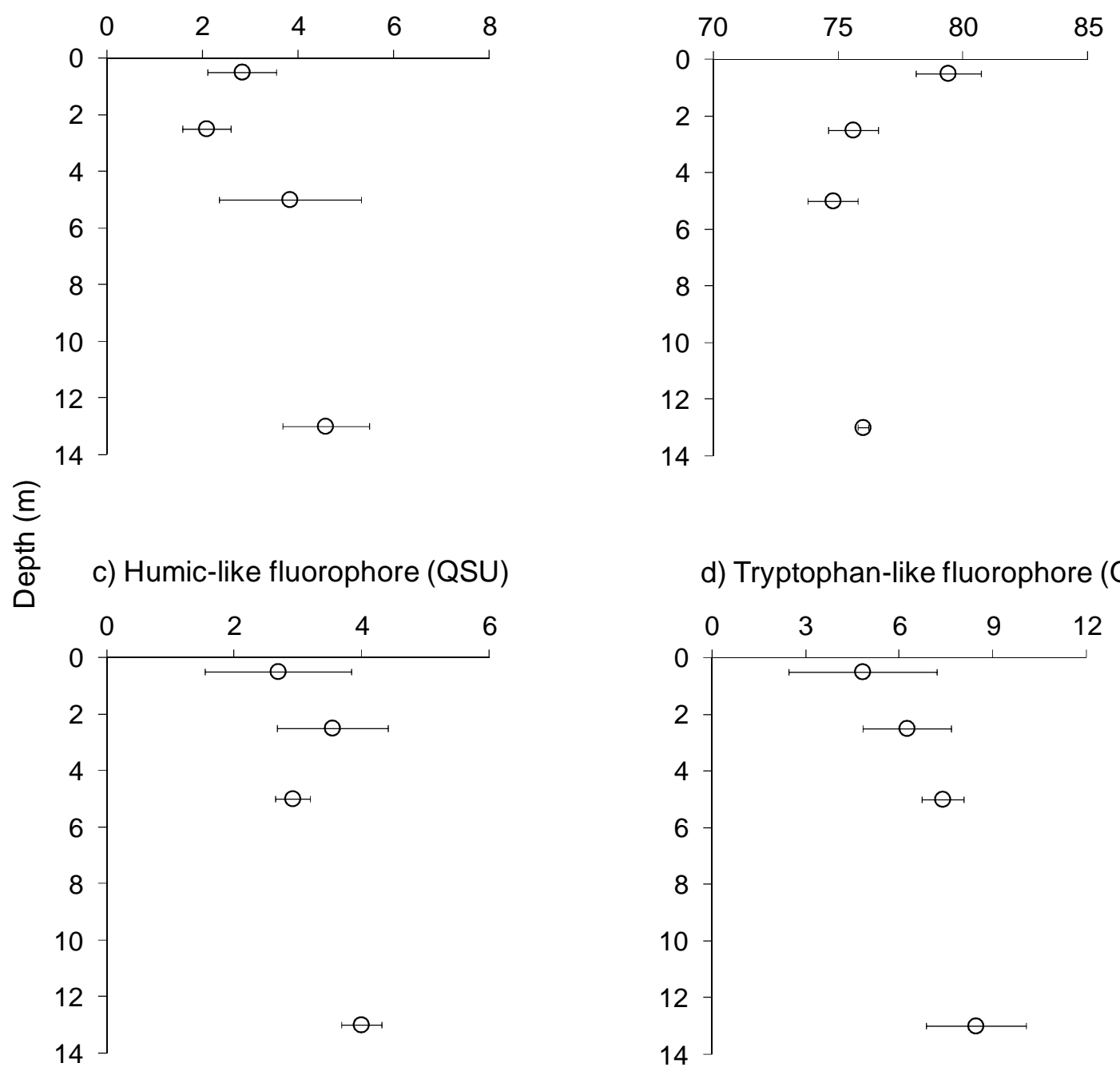

d) Tryptophan-like fluorophore (QSU)

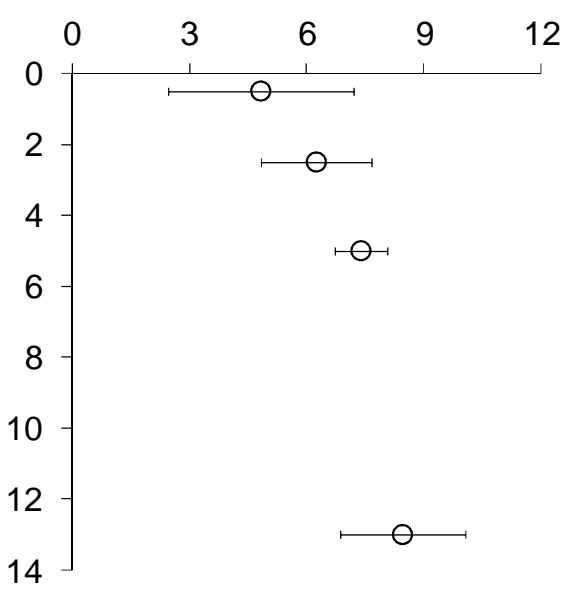

Figure S4. Concentrations in a) dissolved $\Sigma 34$ PAHs $\left(\mathrm{ng} \mathrm{L}^{-1}\right)$, b) DOC $(\mu \mathrm{M})$ and fluorescence intensities of c) humic-like and d) tryptophan-like fluorophores (QSU) with depth in the water column from the MIS site. 


\section{References}

Accardi-Dey, A., Gschwend, P.M., 2002. Assessing the Combined Roles of Natural Organic Matter and Black Carbon as Sorbents in Sediments. Environmental Science and Technology 36, 21-29. Accardi-Dey, A., Gschwend, P.M., 2003. Reinterpreting Literature Sorption Data Considering both Absorption into Organic Carbon and Adsorption onto Black Carbon. Environmental Science and Technology 37, 99-106.

Barhoumi, B., LeMenach, K., Devier, M.H., Ben Ameur, W., Etcheber, H., Budzinski, H., Cachot, J., Driss, M.R., 2014. Polycyclic aromatic hydrocarbons (PAHs) in surface sediments from the Bizerte Lagoon, Tunisia: levels, sources, and toxicological significance. Environmental Monitoring Assessment 186, 2653-2669.

Blumer, M., Guillard, R.R.L., Chase, T., 1971. Hydrocarbons of marine phytoplankton. Marine Biology 8, 183-189.

Bouloubassi, I., Saliot, A., 1993. Investigation of anthropogenic and natural organic inputs in estuarine sediments using hydrocarbon markers (NAH, LAB, PAH). Oceanologica Acta 16, 145-161.

Cornelissen, G., Breedveld, G.D., Kalaitzidis, S., Christanis, K., Kibsgaard, A., Oen, A.M.P., 2006. Strong Sorption of Native PAHs to Pyrogenic and Unburned Carbonaceous Geosorbents in Sediments. Environmental Science and Technology 40, 1197-1203.

Dong, J., Xia, X., Wang, M., Lai, Y., Zhao, P., Dong, H., Zhao, Y., Wen, J., 2015. Effect of watersediment regulation of the Xiaolangdi Reservoir on the concentrations, bioavailability, and fluxes of PAHs in the middle and lower reaches of Yellow River. Journal of Hydrology 527, 101-112.

Douglas, A.G., Eglinton, G., 1966. Distribution of alkanes. In: Swam, T. (eds.). Comparative Phytochemistry. Academic Press, London, New York, pp. 57-77.

Feng, J., Yang, Z., Niu, J., Shen, Z., 2007. Remobilization of polycyclic aromatic hydrocarbons during the resuspension of Yangtze River sediments using a particle entrainment simulator. Environmental Pollution 149, 193-200.

Guo, W., He, M., Yang, Z., Lin, C., Quan, X., Wang, H., 2007. Distribution of polycyclic aromatic hydrocarbons in water, suspended particulate matter and sediment from Daliao Riverwatershed, China. Chemosphere 68, 93-104. 
Jonker, M.T.O., Koelmans, A.A., 2001. Polyoxymethylene Solid Phase Extraction as a Partitioning Method for Hydrophobic Organic Chemicals in Sediment and Soot. Environmental Science and Technology 35, 3742-3748.

Latimer, J.S., Davis, W.R., Keith, D.J., 1999. Mobilization of PAHs and PCBs from in-place contaminated marine sediments during simulated resuspension events. Estuarine, Coastal and Shelf Science 49, 577-595.

Lohmann, R., MacFarlane, J.K., Gschwend, P.M., 2005. Importance of Black Carbon to Sorption of Native PAHs, PCBs, and PCDDs in Boston and New York Harbor Sediments. Environmental Science Technology 39, 141-148.

Long, E.R., Macdonald, D.D., Smith, S.L., Calder, F.D., 1995. Incidence of adverse biological effects with ranges of chemical concentrations in marine and estuarine sediments. Environmental Management 19, 81-97.

Mazurek, M.A., Simoneit, B.R.T., 1984. Characterization of biogenic and petroleum-derived organic matter in aerosols over remote, rural and urban areas. In: Keith, L.H. (ed.). Identification and Analysis of Organic Pollutants in Air. Ann Arbor Science, Boston, pp. 353-370.

Mitra, S., Dellapenna, T.M., Dickut, R.M., 1999a. Polycyclic Aromatic Hydrocarbon Distribution within Lower Hudson River Estuarine Sediments: Physical Mixing vs Sediment Geochemistry. Estuarine, Coastal and Shelf Science 49, 311-326.

Mitra, S., Dickhut, R.M., Kuehl, S.A., Kimbrough, K.L., 1999b. Polycyclic Aromatic Hydrocarbon (PAH) Source, Sediment Deposition Patterns, and Particle Geochemistry as Factors Influencing PAH Distribution Coefficients in Sediments of the Elizabeth River, VA, USA. Marine Chemistry 66, 113-127.

Socha, S.B., Carpenter, R., 1987. Factors affecting pore water hydrocarbonconcentrations in Puget Sound sediments. Geochimica and Cosmochimica 51, 1273-1254.

Tobiszewski, M., Namieśnik, J., 2012. PAH diagnostic ratios for the identification of pollution emission sources. Environmental Pollution 162, 110-119.

Yunker, M.B., Macdonald, R.W., Vingarzan, R., Mitchell, R.H., Goyette, D., Sylvestre, S., 2002. PAHs in the Fraser River basin: a critical appraisal of PAH ratios as indicators of PAH source and composition. Organic Geochemistry 33, 489-515. 
Zaghden, H., Tedetti, M., Sayadi, S., Serbaji, M.M., Elleuch, B., Saliot, A., 2017. Origin and distribution of hydrocarbons and organic matter in the surficial sediments of the Sfax-Kerkennah channel (Tunisia, Southern Mediterranean Sea). Marine Pollution Bulletin 117, 414-428. 